\title{
The crangonid shrimp genus Metacrangon (Crustacea: Decapoda: Caridea) from New Zealand, with descriptions of four new species
}

\author{
Tomoyuki Komai ${ }^{\mathrm{a} *}$ and Shane T. Ahyong ${ }^{\mathrm{b}}$
}

${ }^{a}$ Natural History Museum and Institute, Chiba, 955-2 Aoba-cho, Chuo-ku, Chiba, 260-8682 Japan; ${ }^{b}$ Australian Museum, 6 College Street, Sydney, NSW 2010, Australia

(Received 24 February 2010; final version received 30 August 2010; printed 13 December 2010)

\begin{abstract}
Examination of collections from waters around New Zealand resulted in significant findings of six species of Metacrangon Zarenkov, 1965, a crangonid shrimp genus well represented in the North Pacific: M. knoxi (Yaldwyn, 1960); M. richardsoni (Yaldwyn, 1960); M. hikurangi sp. nov.; M. haona sp. nov.; M. rau sp. nov.; and M. teina sp. nov. The present material includes the second record of the two previously described species since their original descriptions. The four new species are all closely related to $M$. knoxi, suggesting a monophyletic origin of these five species. Differentiating characters among the four new species and $M$. knoxi are discussed in detail. All six species are known only from New Zealand waters, and they are probably endemic to the area.
\end{abstract}

Keywords: Caridea; Crangonidae; Metacrangon; new species; New Zealand

\section{Introduction}

The crangonid shrimp genus Metacrangon Zarenkov, 1965 is currently represented by 25 species and one subspecies (Zarenkov 1965; Fujino and Miyake 1970; Butler 1980; Komai 1994, 1995, 1997; Kim and Hayashi 2003; Retamal and Gorny 2003; Kim 2005; Komai and Komatsu 2009). It is characterized by the shallowly depressed gastric region of the carapace, the usual presence of a pair of submedian teeth on the carapace, the laterally flared pleuron of the sixth abdominal somite, and the second pleopod with an appendix masculina being much shorter than the endopod (Zarenkov 1965; Butler 1980; Kim and Hayashi 2003; Kim 2005). Many species occur in the northern hemisphere (19 species and one subspecies in the North Pacific and one species in the North Atlantic), but five species, namely, M. bahamondei Retamal and Gorny, 2003, M. bellmarleyi (Stebbing, 1914), M. crosnieri Komai, 1997, M. knoxi (Yaldwyn, 1960) and M. richardsoni (Yaldwyn, 1960), are found in the southern hemisphere (Stebbing 1914; Yaldwyn 1960; Komai 1997; Retamal and Gorny 2003). In addition, one undescribed species is known from southwestern Australia, awaiting formal description (Poore et al. 2008; Komai and Taylor, in press). In spite of the rather wide geographic and bathymetric distributions of the genus, many species are restricted to narrow geographic areas or to narrow depth ranges.

Examination of the material in the collections of the National Institute of Water and Atmospheric Research (NIWA) resulted in the significant findings of six species of Metacrangon from waters around New Zealand, including M. knoxi, M. richardsoni

\footnotetext{
*Corresponding author. Email: komai@chiba-muse.or.jp
} 
and four new species, namely, M. haona, M. hikurangi, $M$. rau and $M$. teina. These four new species are all closely related to $M$. knoxi, which is referred to the informal $M$. jacqueti (A. Milne-Edwards, 1881) species group, suggesting a monophyletic origin of the five species restricted to New Zealand waters.

The material examined in this study is deposited in NIWA, the Canterbury Museum, Christchurch (CM), and the Museum of New Zealand Te Papa Tongarewa (MNZ). The measurement provided is of the postorbital carapace length (CL) measured from the level of the posterior margin of the orbit to the midpoint of the posterodorsal margin of the carapace. To avoid repetitious description, only M. teina, for which seven specimens are available for study, is fully described.

\section{Taxonomy}

\section{Metacrangon haona sp. nov.}

(Figures 1-3)

\section{Material examined}

Holotype. Pukaki Rise, Campbell Plateau, 49²1.50’ S, $171^{\circ} 53.00^{\prime}$ E, 353 m, stn D0210, 26 January 1964, male (CL 6.8 mm), NIWA 6257.

\section{Description}

Body (Figures 1, 2A,B) moderately robust. Rostrum (Figures 1, 2A) dorsoventrally flattened, directed slightly dorsally, unusually elongate (0.55 times as long as carapace), reaching distal margin of antennular peduncle, sinuously curved in lateral view; tip acuminate in dorsal view; dorsal surface nearly flat; lateral margin merging into orbital margin; midventral carina low, blunt, present only in proximal half. Carapace (Figures 1, 2A) not widened posteriorly, distinctly longer than wide postorbitally; surface covered with very short setae; dorsal midline with two very prominent, laterally compressed teeth; anterior tooth arcuate, strongly upturned (angle against horizontal plane of carapace about $50^{\circ}$ ), arising distinctly anterior to rostral base, overlapping rostrum, tip slightly falling short of rostral tip; posterior (cardiac) tooth slightly smaller than anterior tooth, hooked, arising at 0.60 of CL; submedian tooth moderately small; hepatic tooth moderately small, followed by epibranchial ridge; antennal tooth moderately small, directed forward in lateral view and somewhat laterally in dorsal view, acuminate; orbital cleft absent; anterolateral margin between antennal and branchiostegal teeth with tiny denticle inferior to base of antennal tooth; branchiostegal tooth slender, recurved, directed laterally in dorsal view and slightly dorsally in lateral view, over-reaching level of dorsodistal margin of antennal basicerite; pterygostomial tooth small, not visible in lateral view; postorbital carina clearly delimited, accompanied by suture; epibranchial carina distinct.

Abdomen (Figures 1, 2B) moderately sculptured; anterior five somites each with distinct, crested mid-dorsal carina, none of mid-dorsal carina on anterior four somites not extending to posterodorsal margin of each somite; mid-dorsal carina on first and second somites produced anterodorsally. First pleuron with blunt, but well-defined tooth at posteroventral angle; second pleuron with triangular tooth at middle of ventral margin; first and second pleura flared laterally, so ventral teeth visible in dorsal 


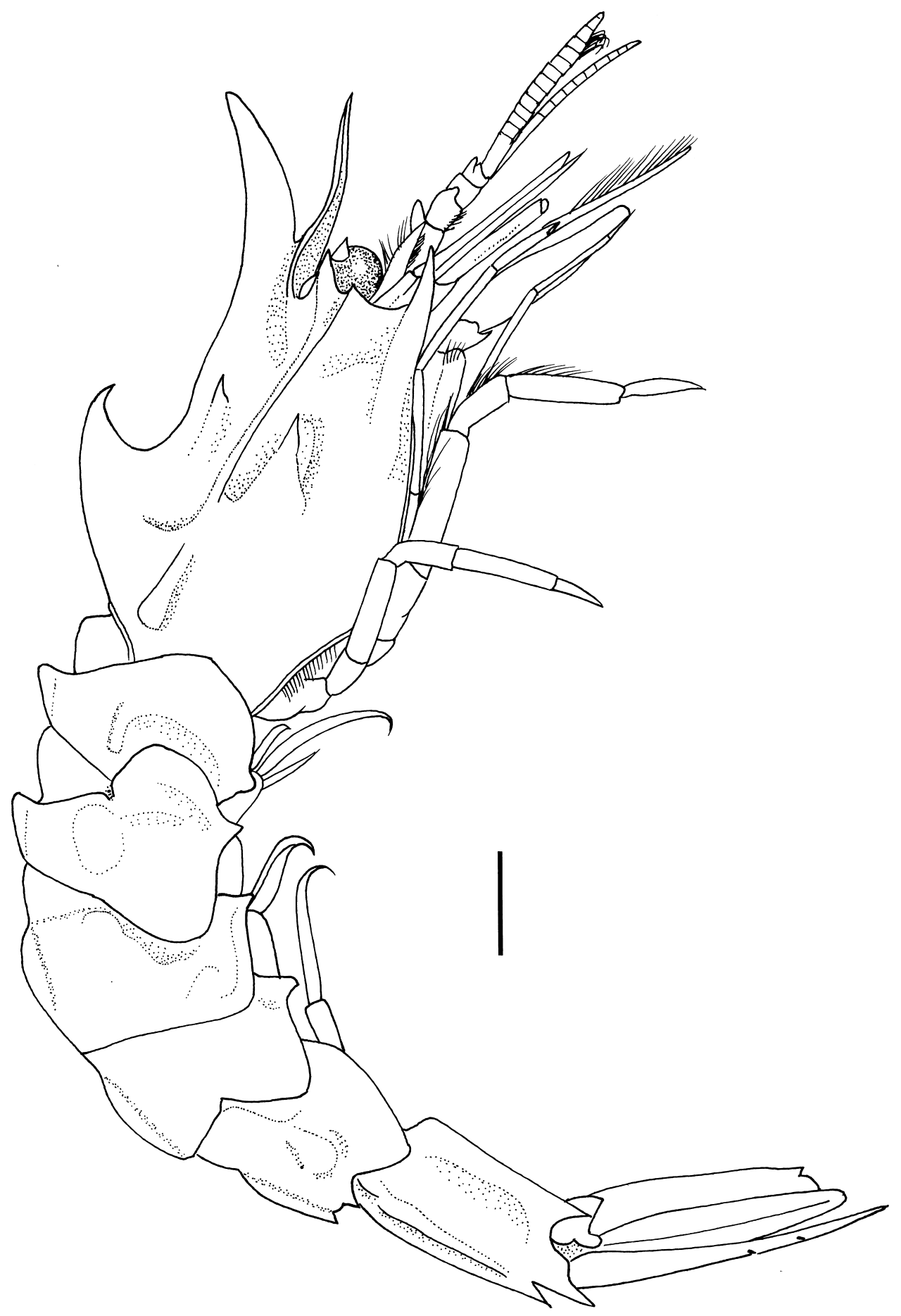

Figure 1. Metacrangon haona sp. nov., holotype, male (CL $6.8 \mathrm{~mm}$ ), NIWA 6257. Entire animal in lateral view. Scale bar: $2 \mathrm{~mm}$. 


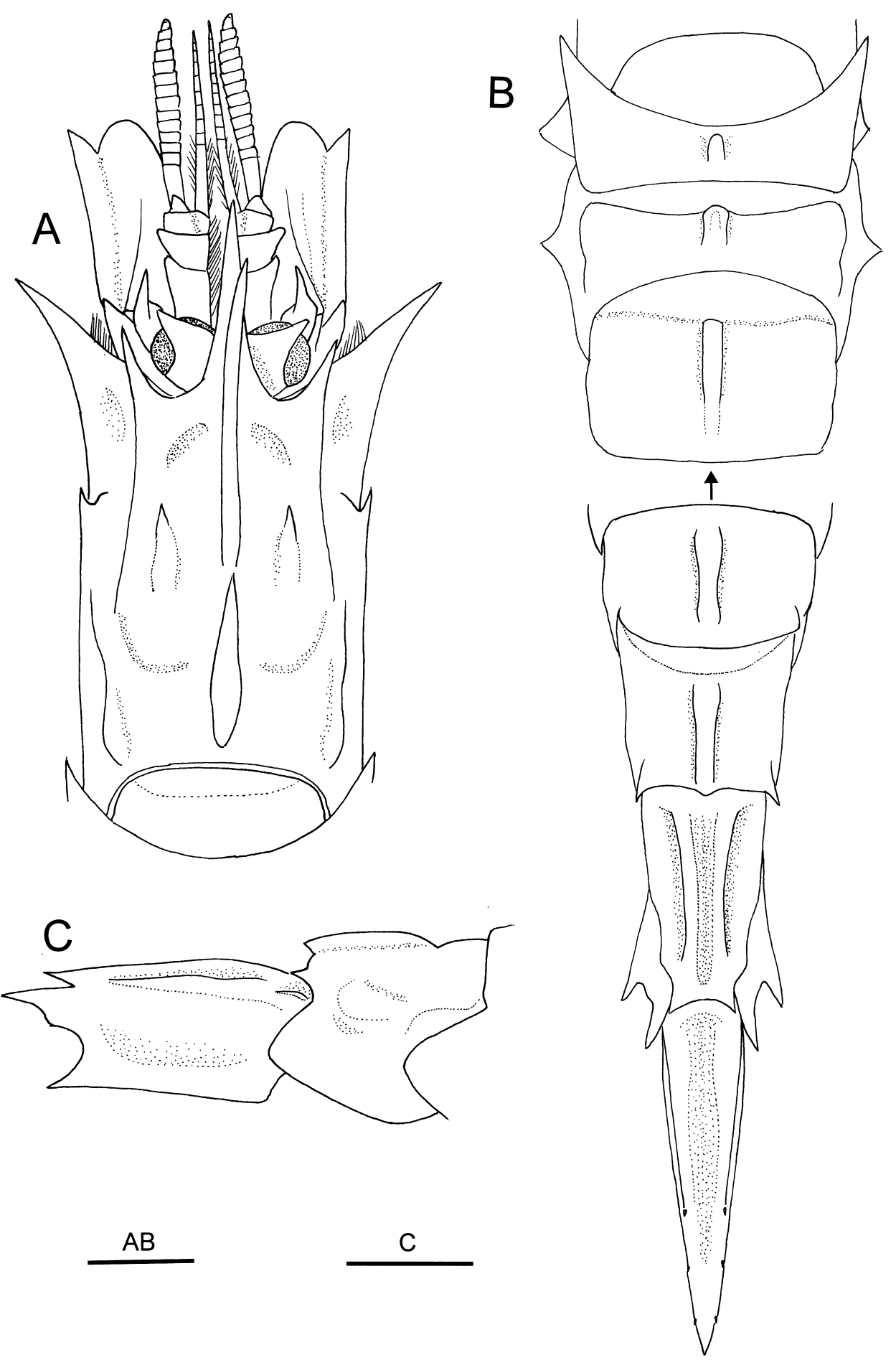

Figure 2. Metacrangon haona sp. nov., holotype, male (CL $6.8 \mathrm{~mm}$ ), NIWA 6257. (A) Carapace and cephalic appendages, dorsal view (setae partially omitted); (B) abdomen, dorsal view (setae omitted); (C) fifth and sixth abdominal somites, lateral view. Scale bars: $2 \mathrm{~mm}$. 
view; third and fourth pleura each with distinct triangular tooth at anteroventral angle. Fifth somite (Figure 2C) with obsolete lateral ridge; dorsal margin nearly straight in lateral view; posterodorsal margin armed with small tooth on either side of median projection; pleuron rounded posteroventrally. Sixth somite 1.7 times longer than wide; submedian carinae distinct, slightly curving, not reaching posterodorsal margin; dorsolateral carina distinct, sinuous posteriorly; posterodorsal margin strongly produced, bi-toothed; pleuron strongly flared laterally, posteroventral tooth strong; posterolateral process strong, somewhat curved laterally, terminating in sharp tooth (Figure 2C). Telson (Figure 2B) with three pairs of dorsolateral spines, anteriormost pair located at posterior 0.4 ; several pairs of plumose setae distal to third pair of lateral spines.

Thoracic sternum widened posteriorly; fifth thoracic sternite with relatively broad, forwardly directed median tooth; sixth to eighth sternites with prominent median keels, those on sixth and seventh sternites each with sharp point anteriorly, that of eighth sternite sharply pointed dentiform. First to fourth abdominal sternites each with prominent median tooth, fifth sternite with short median ridge. Sixth sternite wide, shallowly depressed.

Eye (Figures 2A, 3A) as wide as long; cornea as wide as eyestalk, light greyish brown in preservative, corneal width about 0.20 of CL; eyestalk with prominent, acutely pointed dorsal tubercle over-reaching distal corneal margin.

Antennular peduncle (Figures 2A, 3A) reaching midlength of antennal scale. First segment with prominent, blunt distolateral process curving anteriorly, distomesial margin unarmed; stylocerite terminating in acute tooth, slightly falling short of tip of distolateral process of first segment, lateral margin obtusely angular. Second segment much wider than long, widened distally, with prominent, blunt distolateral process. Third segment wider than long. Outer flagellum over-reaching distal margin of lamella of antennal scale by 0.6 length, consisting of 14 or 15 articles.

Antennal basicerite (Figures 2A, 3A) stout, with produced, acutely pointed dorsodistal lateral angle, ventrolateral tooth reaching beyond dorsodistal lateral angle. Antennal scale 0.53 times as long as carapace and 2.3 times longer than wide; lateral margin nearly straight; distolateral tooth moderately wide, just reaching rounded distal margin of lamella.

Third maxilliped relatively slender, over-reaching antennal scale by half length of ultimate segment; ultimate segment (Figure 3B) gradually tapering distally, about 7.5 times longer than wide; penultimate segment about 3.3 times longer than wide (Figure 3B); antepenultimate segment unarmed on ventral surface.

First pereopod (Figure 3C,D) reaching distal margin of antennal scale; palm 3.3 times longer than wide, not widened proximally or distally, lateral and mesial margins slightly sinuous; thumb relatively slender; carpus with small ventrolateral tooth; merus with one small dorsodistal tooth, ventral margin sinuous, crested. Second pereopod (Figure 3E) reaching nearly to midlength of antennal scale; dactylus about 0.3 times as long as palm; length ratio of chela to merus $1: 1.7: 1.8$. Third pereopod (Figure $3 \mathrm{~F}$ ) nearly reaching distal margin of antennal scale by tip of dactylus; length ratio of dactylus to ischium $1: 1.9: 3.2: 2.3: 2.2$. Fourth pereopod (Figure $3 \mathrm{G}$ ) moderately slender, slightly over-reaching distal margin of antennal scale by dactylus; dactylus (Figure $3 \mathrm{H}$ ) narrowly spatulate, about 0.7 times as long as propodus, margins naked; dactylus-propodus articulation about $60^{\circ}$; propodus about 4.5 times longer than wide. Fifth pereopod (Figure 3I) slightly shorter than fourth pereopod, 

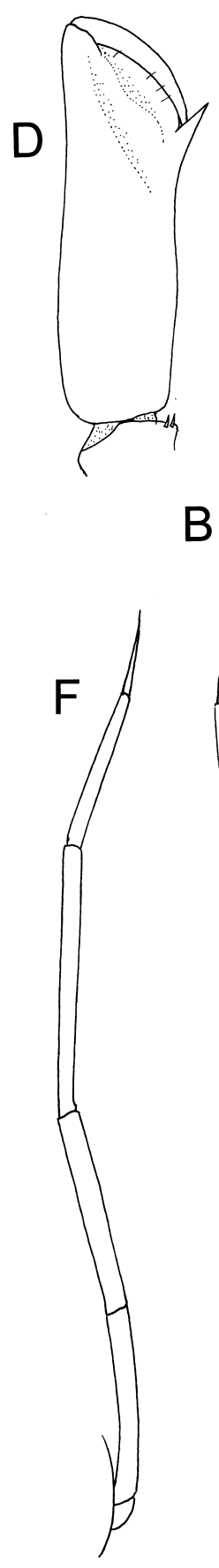
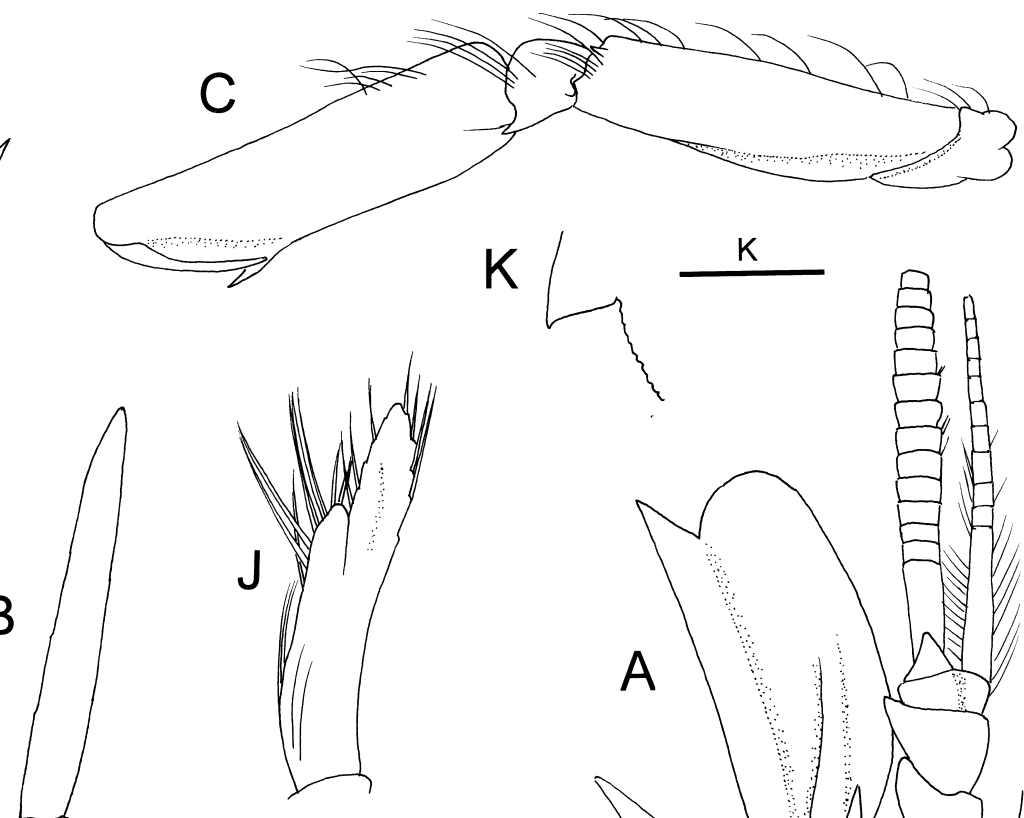
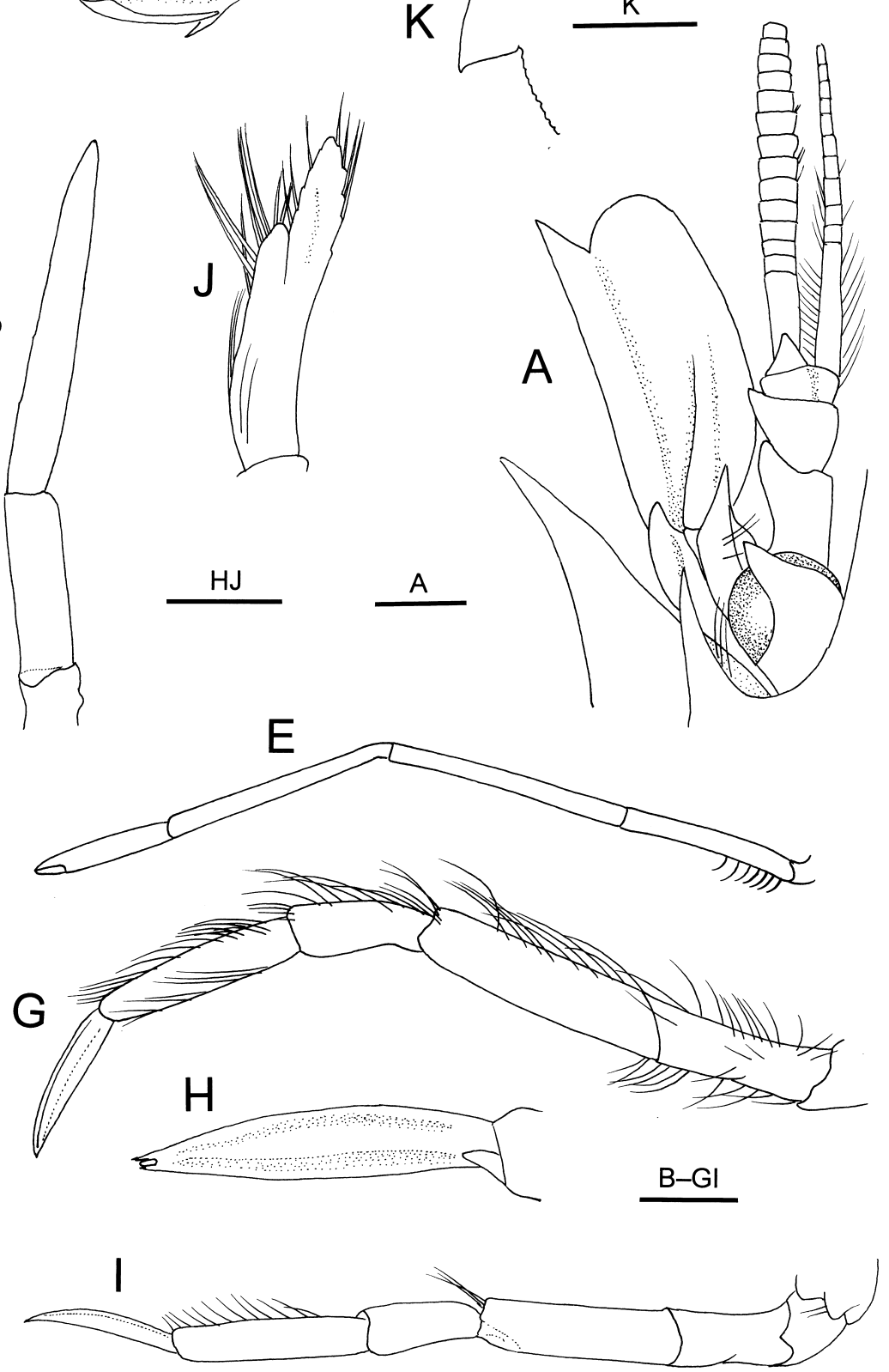

Figure 3. Metacrangon haona sp. nov., holotype, male (CL $6.8 \mathrm{~mm}$ ), NIWA 6257. (A) Left eye, antennule and antenna, dorsal view (setae partially omitted); (B) distal two segments of left 
slightly over-reaching base of branchiostegal tooth; dactylus subspatulate, about 0.70 times as long as propodus.

Second pleopod with appendix masculina reaching distal 0.30 of endopod, bearing about 10 spiniform setae (Figure $3 \mathrm{~J}$ ). Uropodal exopod with nearly straight lateral margin, posterolateral tooth acute (Figure $3 \mathrm{~K}$ ); no spinule mesial to posterolateral tooth.

\section{Colouration in life}

Not known.

Size

The only known specimen is a mature male, CL $6.8 \mathrm{~mm}$.

\section{Distribution}

Known only from Pukaki Rise, Campbell Plateau, at depth of $353 \mathrm{~m}$.

\section{Etymology}

From the Maori word "haona", meaning horn, in reference to the unusually elongate rostrum and prominent, horn-like anterior mid-dorsal tooth of the carapace.

Metacrangon hikurangi sp. nov.

(Figures 4-6)

\section{Material examined}

Holotype. Hikurangi Margin, east coast of North Island, New Zealand, $40^{\circ} 02.22-$ 02.14' S, 17748.06-47.97' E, 1171-1172 m, RV Sonne, SO191-3/241, 7 March 2007, female (CL $10.6 \mathrm{~mm}$ ), NIWA 31943.

\section{Description}

Body (Figures 4, 5A,D) moderately robust. Rostrum (Figures 4, 5A,B) dorsoventrally flattened, narrowly subtriangular in dorsal view, directed forward, about 0.2 times as long as carapace; tip rounded in dorsal view; dorsal surface faintly concave in distal half, slightly carinate medially in posterior half; lateral margin nearly straight in lateral view, merging into orbital margin; midventral carina low, ventral margin nearly straight in lateral view. Carapace (Figures 4, 5A) not widened posteriorly, distinctly

third maxilliped, ventral view (setae omitted); (C) left first pereopod, lateral view; (D) same, subchela, dorsal (extensor) view; (E) left second pereopod, lateral view; (F) right third pereopod, lateral view; $(G)$ left fourth pereopod, lateral view; $(H)$ same, dactylus, outer (flexor) view; (I) left fifth pereopod, lateral view; $(\mathrm{J})$ endopod and appendix masculina of left second pleopod, mesial view; (K) posterolateral part of uropodal exopod, dorsal view (setae omitted). Scale bars: $1 \mathrm{~mm}$ for A, C-G, I; $0.5 \mathrm{~mm}$ for $\mathrm{H}, \mathrm{J}, \mathrm{K}$. 


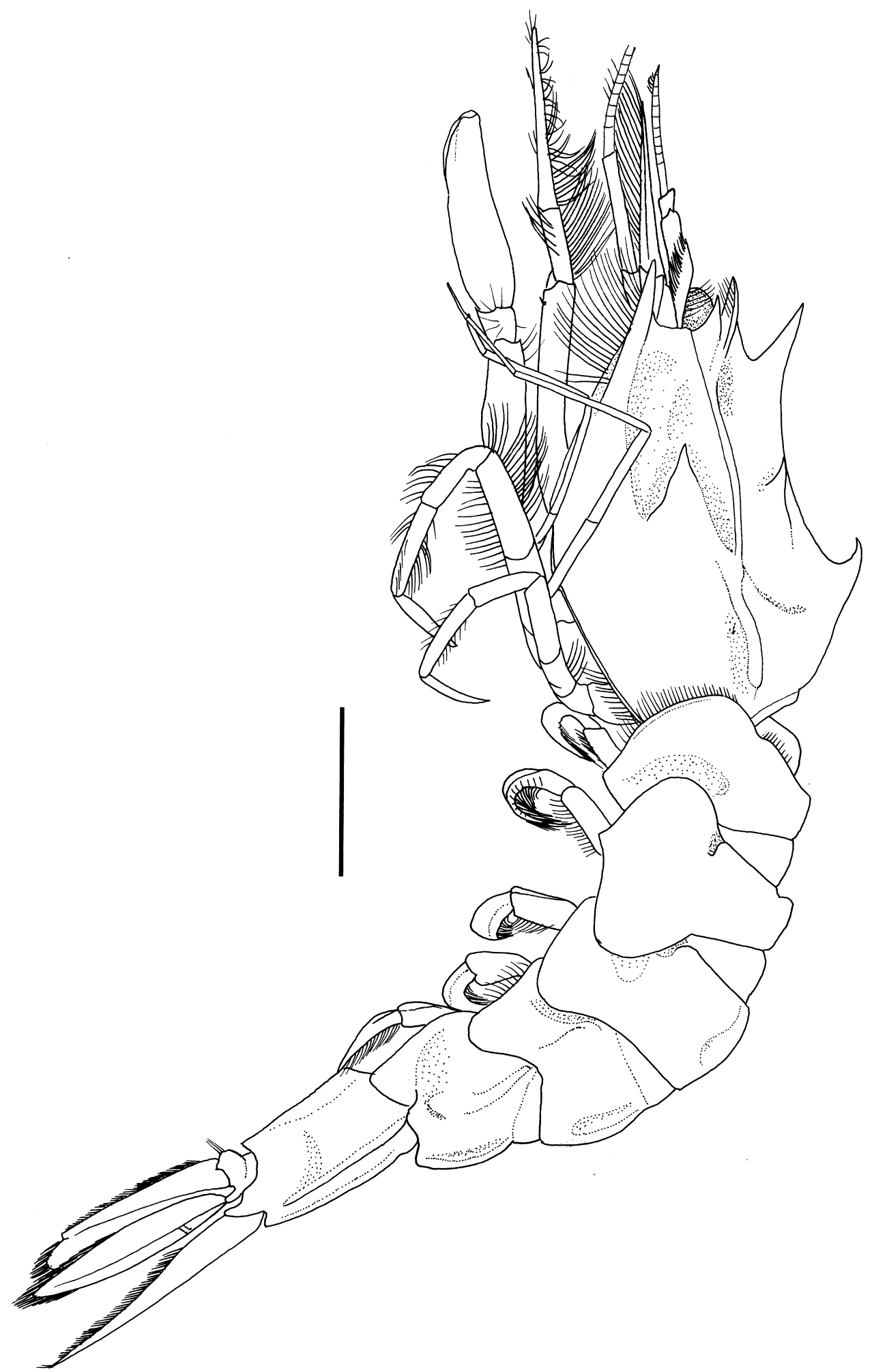

Figure 4. Metacrangon hikurangi sp. nov., holotype, female (CL 10.6 mm), NIWA 31943. Entire animal in lateral view. Scale bar: $5 \mathrm{~mm}$. 


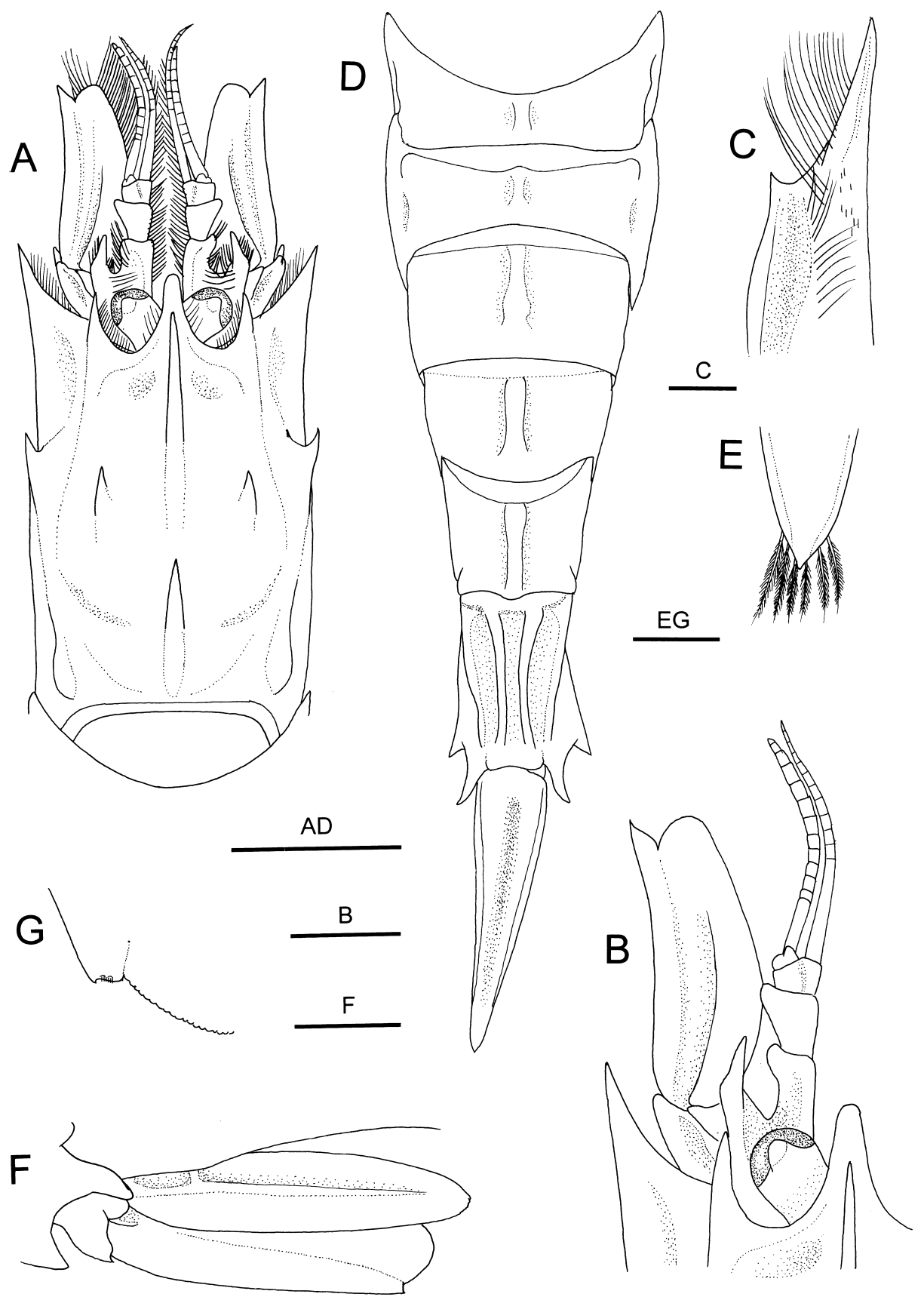

Figure 5. Metacrangon hikurangi sp. nov., holotype, female (CL $10.6 \mathrm{~mm}$ ), NIWA 31943. (A) Carapace and cephalic appendages, dorsal view (setae partially omitted); (B) anterior part of carapace (left) and cephalic appendages, dorsal view (setae omitted); (C) pterygostomial part of carapace (left), ventral view; (D) abdomen and telson, dorsal view; (E) posterior part of telson, dorsal view; (F) left uropod, dorsal view (perpendicular; setae omitted); $(G)$ posterolateral part of uropodal exopod, dorsal view. Scale bars: $5 \mathrm{~mm}$ for A, D; $2 \mathrm{~mm}$ for B, F; $1 \mathrm{~mm}$ for C; $0.5 \mathrm{~mm}$ for $\mathrm{E}, \mathrm{G}$. 

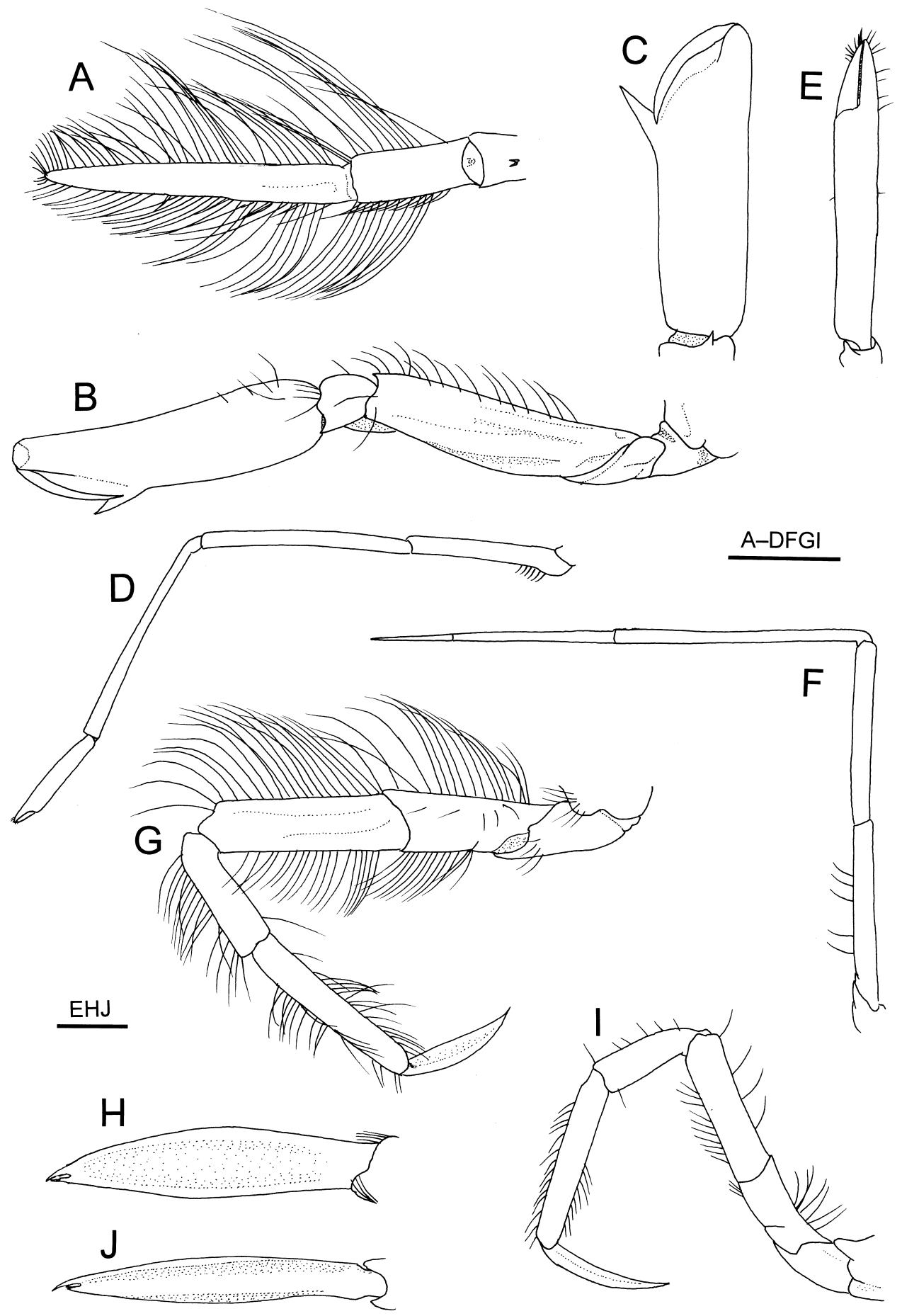

Figure 6. Metacrangon hikurangi sp. nov., holotype, female (CL 10.6 mm), NIWA 31943. Left thoracic appendages. (A) Distal two segments of third maxilliped, ventral view; (B) first pereopod, lateral view; (C) same, subchela, ventral view (setae omitted); (D) second pereopod, 
longer than wide postorbitally; surface covered with very short setae; dorsal midline with two prominent, laterally compressed teeth; anterior tooth styliform, arising slightly posterior to rostral base, somewhat ascending (angle against horizontal plane of carapace about $50^{\circ}$ ), overlapping rostrum, tip falling short of rostral tip; posterior (cardiac) tooth slightly smaller than anterior tooth, hooked, arising at 0.65 of CL; submedian tooth moderately large; hepatic tooth moderately large, followed by clearly delineated epibranchial ridge; antennal tooth moderately small, directed forward in both dorsal and lateral views, acuminate, slightly falling short of rostral tip; orbital cleft absent; anterolateral margin between antennal and branchiostegal teeth concave, with minute denticle inferior to base of antennal tooth; branchiostegal tooth strong, directed forward in dorsal view, slightly ascending in lateral view, reaching dorsodistal margin of antennal basicerite; pterygostomial tooth small (Figure 5C), not visible in lateral view; postorbital carina clearly delimited, accompanied by suture; epibranchial carina distinct.

Abdomen (Figures 4, 5D) weakly sculptured; anterior five somites each with broad, distinctly delimited mid-dorsal carina, mid-dorsal carina on anterior four somites not extending to posterodorsal margin; anterior end of mid-dorsal carina on second somite slightly projecting anteriorly. First pleuron with blunt tooth at posteroventral angle; second pleuron with obtuse tooth at middle of ventral margin; third pleuron without conspicuous tooth or projection on ventral margin; fourth pleuron with faintly concave ventral margin, posterolateral margin rounded. Fifth somite with posterodorsal margin slightly produced medially, posterolateral margin unarmed; pleuron shallowly concave on lateral surface. Sixth somite 1.6 times longer than wide submedian carinae distinct, slightly curving, not reaching posterodorsal margin; dorsolateral carina distinct; posterodorsal margin faintly bilobed; pleuron flared laterally, posteroventral tooth moderately strong; posterolateral process elongate, somewhat curved laterally, terminating in blunt tip. Telson (Figure 5D) without dorsolateral spines; tip acute, with three pairs of plumose setae (Figure 5E).

Thoracic sternum widened posteriorly; fifth sternite with thick median carina bearing small acute tooth directed ventrally; sixth to eighth sternites with thick median carina becoming lower posteriorly. Abdominal sternites bearing sharp tooth in first to third somites, blunt tubercle in fourth and fifth somites; sixth sternite shallowly depressed medially.

Eye (Figure 5A,B) slightly longer than wide; cornea as wide as proximal part of eyestalk, darkly pigmented, corneal width about 0.13 of CL; eyestalk with papilla-like dorsal tubercle.

Antennular peduncle (Figure 5A,B) slightly falling short of midlength of antennal scale. First segment with short, blunt distolateral process, distomesial margin unarmed; stylocerite directed forward, terminating in acute tooth, slightly overreaching tip of distolateral process of first segment, lateral margin slightly angular. Second segment distinctly widened distally, with short, blunt distolateral process.

lateral view; (E) same, chela, lateral view; (F) third pereopod, lateral view; (G) fourth pereopod, lateral view; (H) same, dactylus, flexor view; (I) fifth pereopod, lateral view; (J) same, dactylus, flexor view. Scale bars: $2 \mathrm{~mm}$ for A-D, F, G, I; $1 \mathrm{~mm}$ for E, H, J. 
Third segment wider than long. Outer flagellum over-reaching distal margin of lamella of antennal scale by 0.4 length, consisting of 13 articles.

Antennal basicerite (Figure 5A,B) stout, with sharply pointed dorsodistal lateral angle, ventrolateral tooth exceeding beyond dorsodistal lateral angle. Antennal scale 0.50 times as long as carapace and 2.7 times longer than wide; lateral margin slightly concave; distolateral tooth moderately wide, slightly over-reaching rounded distal margin of lamella.

Third maxilliped relatively slender, over-reaching antennal scale by half length of ultimate segment; ultimate segment (Figure 6A) gradually tapering distally, about 7.3 times longer than wide; penultimate segment about 2.4 times longer than wide (Figure 6A); antepenultimate segment with two minute spinules subdistally on ventral surface.

First pereopod (Figure 6B,C) reaching distal margin of antennal scale; palm 3.4 times longer than wide, not widened proximally or distally, lateral and mesial margins nearly straight; thumb relatively slender; carpus with small ventrolateral tooth; merus with one small dorsodistal tooth, ventral margin sinuous, crested. Second pereopod (Figure 6D) reaching nearly to midlength of antennal scale; dactylus about 0.4 times as long as palm (Figure 6E); length ratio of chela to ischium $1: 1.9: 1.8: 1.3$. Third pereopod (Figure 6F) nearly reaching distal margin of antennal scale by tip of dactylus; length ratio of dactylus to ischium $1: 2.0: 3.1: 2.1: 2.3$. Fourth pereopod (Figure 6G) moderately stout, slightly over-reaching midlength of antennal scale by dactylus; dactylus (Figure $6 \mathrm{H}$ ) narrowly spatulate, about 0.7 times as long as propodus, margins naked; dactylus-propodus articulation about $45^{\circ}$; propodus about 5.6 times longer than wide. Fifth pereopod (Figure 6I) shorter than fourth pereopod, reaching base of branchiostegal tooth; dactylus (Figure 6J) subspatulate, more slender than that of fourth pereopod, about 0.7 times as long as propodus; setation much less than in fourth pereopod.

Uropodal exopod (Figure 5F,G) with subtruncate posterolateral tooth; no spinule mesial to posterolateral tooth (Figure $5 \mathrm{G}$ ).

\section{Colouration in life}

Not known.

Size

The only known specimen is a female of pre-spawning moult, CL $10.6 \mathrm{~mm}$.

\section{Distribution}

Known only from east coast of North Island of New Zealand, at depths of 1171$1172 \mathrm{~m}$.

Figure 7. Metacrangon rau sp. nov., holotype, male (CL $5.4 \mathrm{~mm}$ ), NIWA 6329. Entire animal in lateral view (setae partially omitted). 


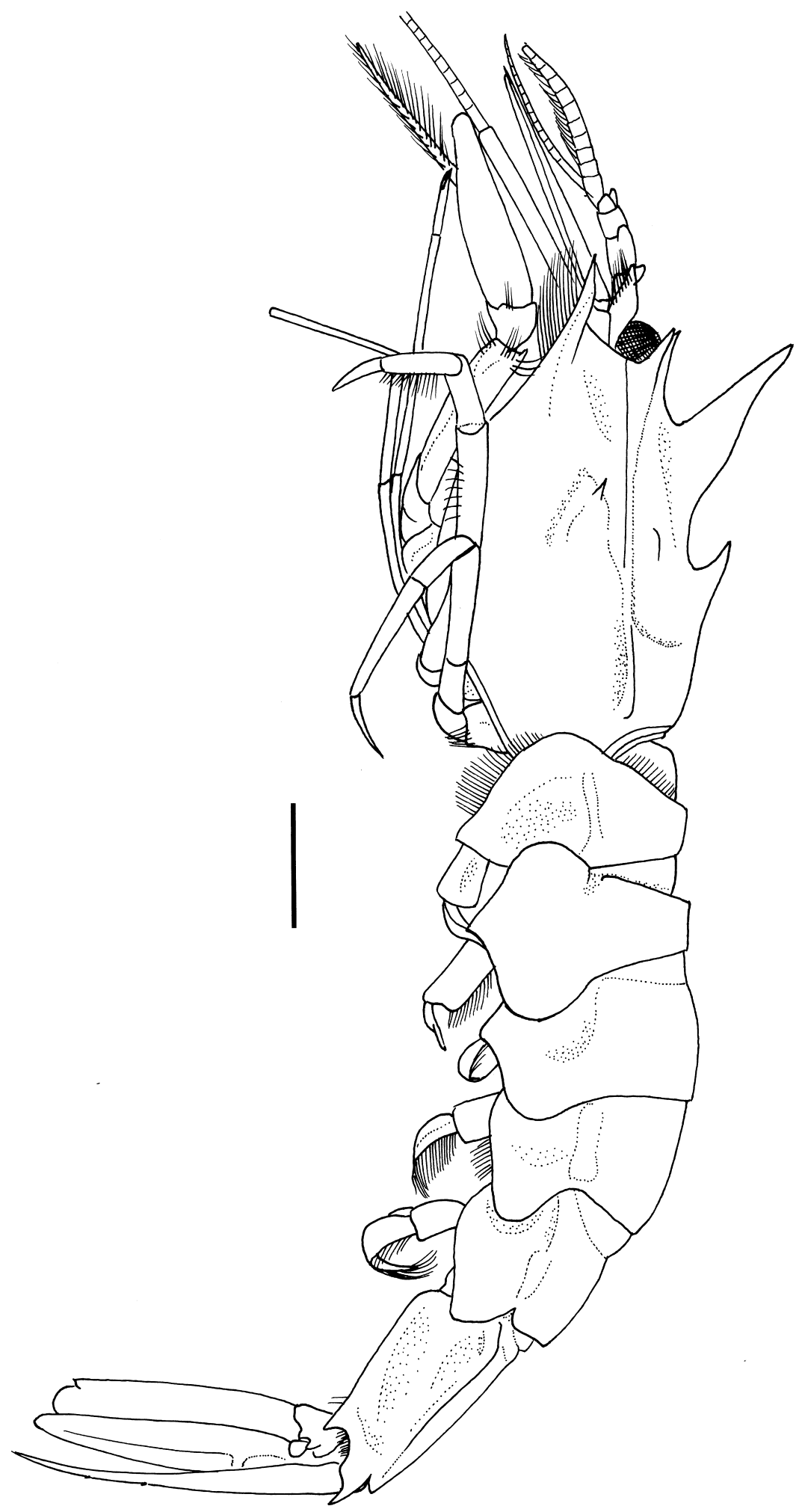




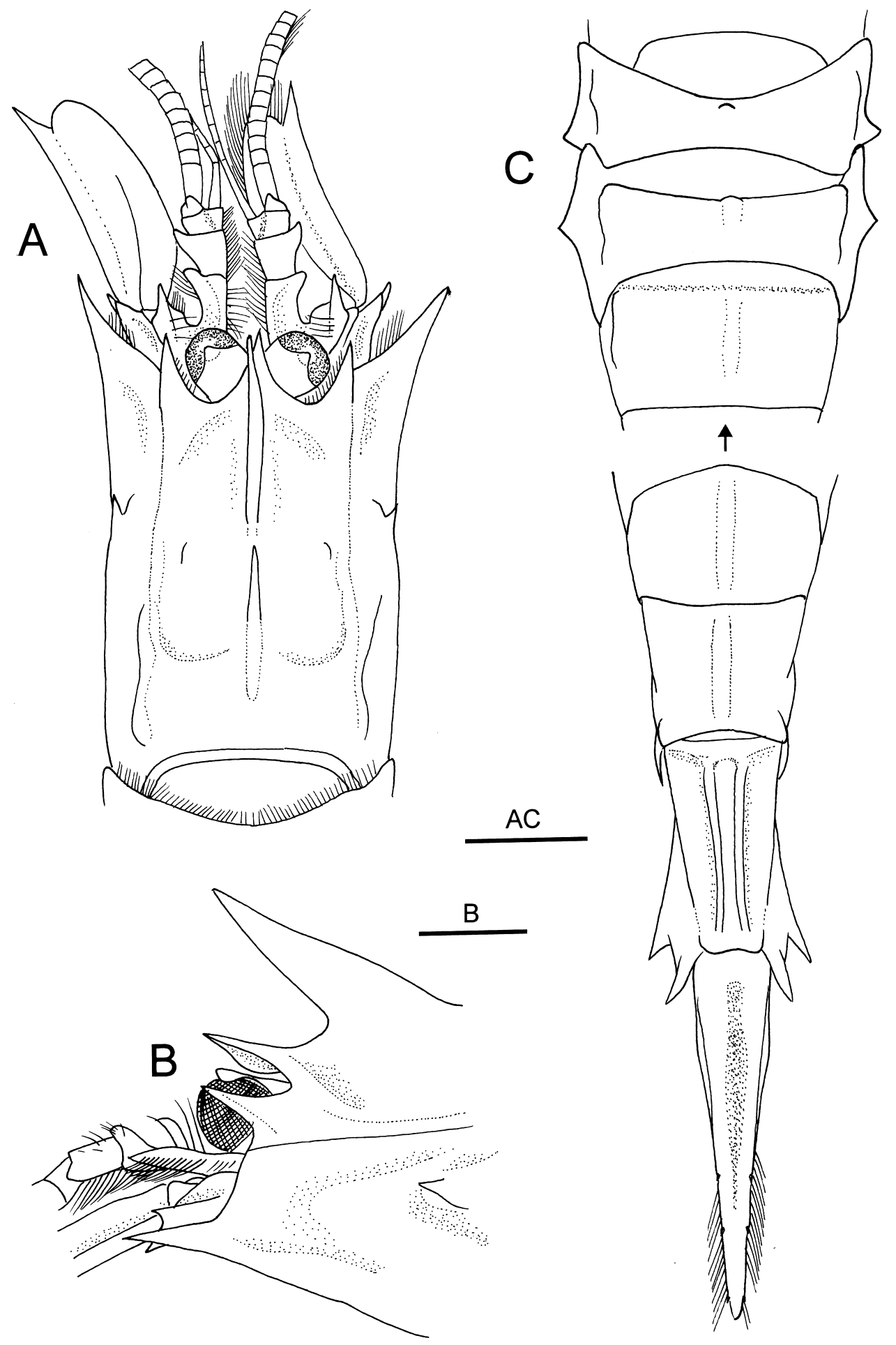

Figure 8. Metacrangon rau sp. nov., holotype, male (CL $5.4 \mathrm{~mm}$ ), NIWA 6329. (A) Carapace and cephalic appendages, dorsal view (setae partially omitted); (B) anterior part of carapace, 


\section{Etymology}

Named for the type locality; used as a noun in apposition.

\section{Metacrangon rau sp. nov.}

(Figures 7-10)

\section{Material examined}

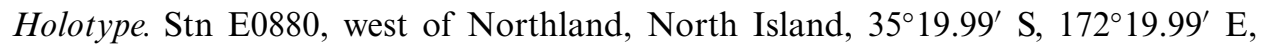
1029-1074 m, 22 March 1968, male (CL 5.4 mm), NIWA 6329.

Paratypes. Stn P0927, Challenger Plateau, $40^{\circ} 50.09^{\prime} \mathrm{S}, 168^{\circ} 14.80^{\prime} \mathrm{E}, 1009-1005 \mathrm{~m}, 18$ April 1980, male (CL $4.9 \mathrm{~mm}$ ), two females (CL 6.7-7.9 mm), NIWA 11799.

\section{Description}

Body (Figures 7, 8A,C) moderately robust. Rostrum (Figures 8A,B, 10A,C) dorsoventrally flattened, triangular with acute or subacute apex in dorsal view, slightly ascending, about 0.2 times as long as carapace; dorsal surface nearly flat; lateral margin nearly straight in lateral view, merging into orbital margin; midventral carina low, ventral margin sinuous. Carapace (Figures 7, 8A,B, 10B,D) not widened posteriorly, distinctly longer than wide postorbitally; surface covered with very short setae; dorsal midline with two prominent, laterally compressed teeth; anterior tooth very large, blade-like, with sinuous to straight dorsal margin, arising distinctly posterior to rostral base, strongly ascending (angle against horizontal plane of carapace about $55^{\circ}$ ), overlapping rostrum, tip reaching rostral tip; posterior (cardiac) tooth hooked, arising at $0.49-0.52$ of CL; submedian tooth small (in paratypes) or reduced to rudimentary protuberance (in holotype); hepatic tooth small, followed by epibranchial ridge; postorbital carina low, blunt, accompanied by suture; antennal tooth relatively large, acuminate, reaching or under-reaching rostral tip, directed forward in dorsal view, slightly ascending in lateral view; orbital cleft absent; anterolateral margin between antennal and branchiostegal teeth unarmed; branchiostegal tooth strong, curved slightly laterally in dorsal view, slightly ascending in lateral view, distinctly over-reaching dorsodistal margin of antennal basicerite; pterygostomial tooth small, not visible in lateral view.

Abdomen (Figures 7, 8C) slightly sculptured; anterior three somites with trace of mid-dorsal carina, fourth somite with low, blunt, but clearly delimited mid-dorsal carina. First pleuron with subacute tooth ventrally; second pleuron with subacute tooth at middle of ventral margin; ventral margin of first and second pleura flared laterally, so ventral teeth visible in dorsal view; third pleuron with subacute tooth at anteroventral angle; fourth pleuron unarmed. Fifth somite with low, but distinct middorsal carina; posterodorsal margin barely produced medially, posterolateral margin unarmed; pleuron shallowly concave on lateral surface; ventral margin sinuous, posteroventral angle rounded. Sixth somite with distinct, slightly curved submedian

left eye, basal parts of antennae, obliquely lateral view; (C) abdomen and telson, dorsal view. Scale bars: $2 \mathrm{~mm}$ for A, C; $1 \mathrm{~mm}$ for B. 

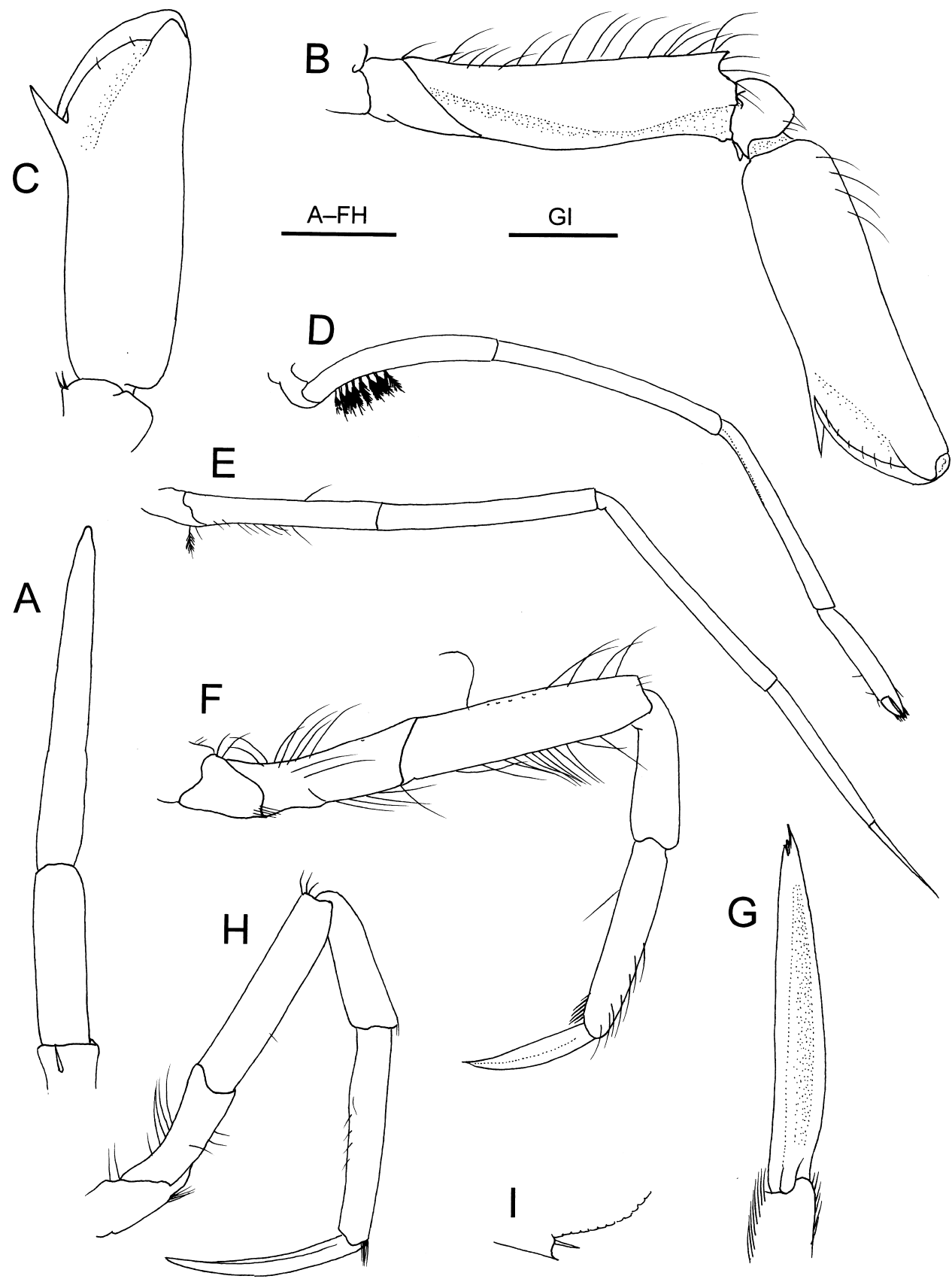

Figure 9. Metacrangon rau sp. nov., holotype, male (CL $5.4 \mathrm{~mm}$ ), NIWA 6329. (A) Distal two segments of right third maxilliped, ventral (flexor) view; (B) right first pereopod, lateral view; (C) same, subchela, dorsal (extensor) view; (D) right second pereopod, lateral view; (E) right third pereopod, lateral view; $(F)$ right fourth pereopod, lateral view; $(G)$ dactylus of left fourth pereopod, flexor view; $(\mathrm{H})$ right fifth pereopod, lateral view; (I) posterolateral part of uropodal exopod, dorsal view (setae omitted). Scale bars: $1 \mathrm{~mm}$ for A-F, H; $0.5 \mathrm{~mm}$ for G, I. 


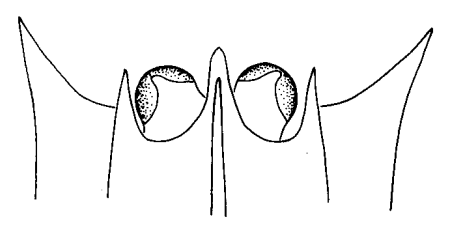

A

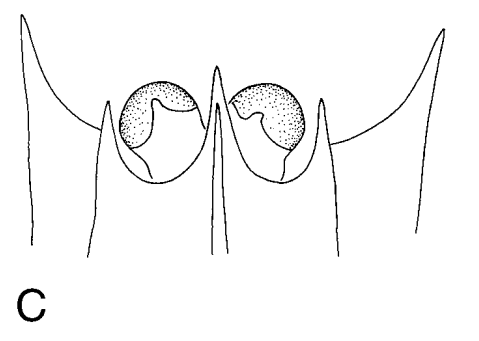

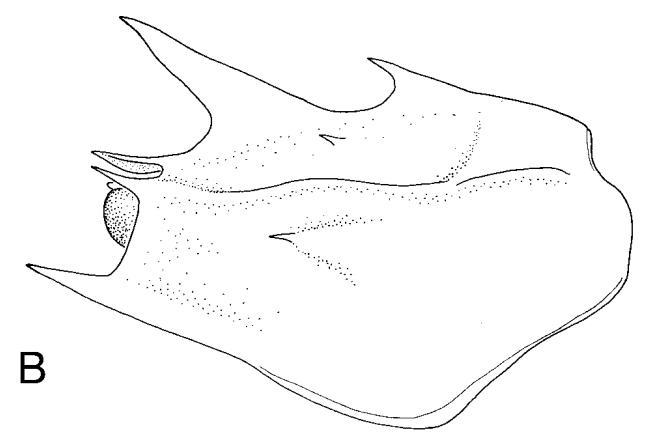

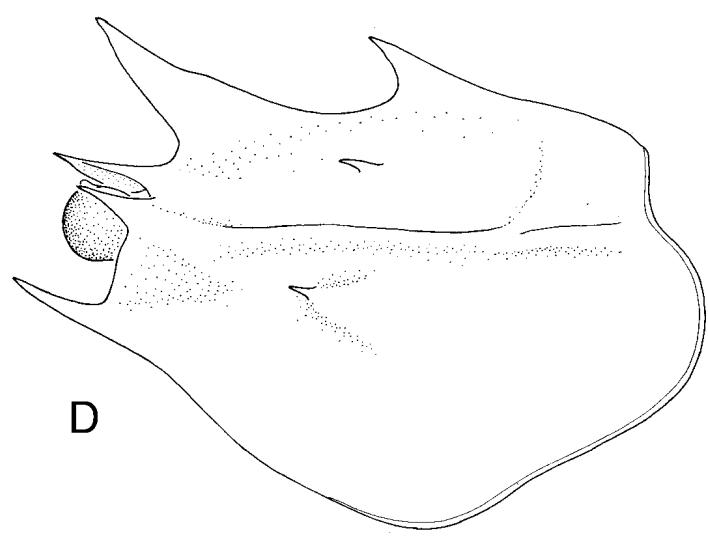

Figure 10. Metacrangon rau sp. nov. (A,B) Paratype, female, non-spawning moult (CL $6.7 \mathrm{~mm}$ ), NIWA 11799. (C,D) Paratype, female, spawning moult (CL 7.9 mm), NIWA 11799. A, C, anterior carapace, dorsal view. B, D, carapace, left lateral view. Scale bar $1 \mathrm{~mm}$.

carinae, not reaching posterodorsal margin; dorsolateral carina distinct; posterodorsal margin faintly bilobed; pleuron flared laterally, posteroventral tooth strong; posterolateral process elongate, directed somewhat laterally, terminating in sharp tooth. Telson (Figure 8C) with three pairs of dorsolateral spines, first pair located at about posterior 0.4 ; tip subacute.

Male fifth to eighth thoracic sternites each with sharply pointed median tooth; first to fourth abdominal sternites each with long, anteriorly curved median tooth; fifth sternite with short median carina. In spawning moult of female, fifth thoracic sternite with thin, triangular carina with acute apex directed ventrally; sixth sternite with low, thin median carina; seventh and eighth sternites unarmed, without median tooth or carina; first to third abdominal sternites unarmed; fourth and fifth sternites with low median carina. In non-spawning moult, fifth thoracic sternite bearing sharp, procurved tooth; sixth to eighth sternites each with low, thin median carina; first to fourth abdominal sternites with ventrally directed tooth; fifth sternite with blunt tubercle. Sixth abdominal sternite medially depressed.

Eye (Figure 8A,B) about as long as wide; cornea as wide as eyestalk, darkly pigmented, corneal width 0.17 of CL; eyestalk with papilla-like dorsal tubercle. 
Antennular peduncle (Figure 8A) reaching midlength of antennal scale. First segment with prominent, subacutely pointed distolateral process, distomesial margin unarmed; stylocerite directed forward, terminating in acute tooth slightly falling short of tip of distolateral process of first segment, lateral margin angular. Second segment distinctly widened distally, with blunt distolateral process. Third segment wider than long. Outer flagellum broken off in distal part, but preserved part over-reaching distal margin of lamella, with 12 articles.

Antennal basicerite (Figure 8A) stout, with sharply pointed dorsodistal lateral angle, ventrolateral tooth small, slightly over-reaching dorsodistal lateral angle. Antennal scale about 0.60 times as long as carapace and 2.6 times longer than wide; lateral margin very slightly concave; distolateral tooth relatively narrow, distinctly over-reaching rounded distal margin of lamella.

Third maxilliped relatively slender, over-reaching antennal scale by half length of ultimate segment; ultimate segment (Figure 9A) gradually tapering distally, about 7.7 times longer than wide; penultimate segment (Figure 9A) about 3.3 times longer than wide; antepenultimate segment with pair of greatly unequal movable spinules subdistally on ventral surface.

First pereopod (Figure 9B,C) moderately stout, reaching distal margin of antennal scale; palm 3.3 times longer than wide, not widened proximally or distally, lateral and mesial margins faintly sinuous, cutting edge oblique; thumb relatively slender; carpus with small ventrolateral tooth; merus with small dorsodistal tooth, ventral margin sinuous, crested. Second pereopod (Figure 9D) reaching nearly to midlength of antennal scale; dactylus about 0.4 times as long as palm; length ratio of chela to merus $1: 1.6: 1.7$. Third pereopod (Figure 9E) slender, nearly reaching distal margin of antennal scale by tip of dactylus; length ratio of dactylus to ischium $1: 1.6: 2.6: 2.1: 1.9$. Fourth pereopod (Figure 9F) moderately stout for genus, slightly falling short of distal margin of antennal scale by dactylus; dactylus (Figure 9G) narrowly spatulate, about 0.7 times as long as propodus, margins naked; dactyluspropodus articulation about $45^{\circ}$; propodus about 4.5 times longer than wide. Fifth pereopod (Figure $9 \mathrm{H}$ ) slightly shorter than fourth pereopod, reaching proximal 0.3 of antennal scale; dactylus subspatulate, more slender than that of fourth pereopod, about 0.9 times as long as propodus; setation much less than in fourth pereopod.

Second pleopod with appendix masculina reaching midlength of endopod, bearing about 10 spiniform setae.

Posterolateral tooth of uropodal exopod truncate with minute lateral denticle (Figure 9I); spinule mesial to posterolateral tooth present.

\section{Colouration in life}

Not known.

\section{Size}

Largest male CL $5.4 \mathrm{~mm}$; largest female (spawning moult) CL $7.9 \mathrm{~mm}$.

\section{Remarks}

Metacrangon rau sp. nov. is known from males and females, which are similar in most respects. Apart from sexual differences (i.e. differences in thoracic and abdominal 
sternal ornamentation), the chief variation noted is in the rostral apex and condition of the submedian teeth of the carapace. The rostrum varies from reaching as far as, to slightly beyond the apices of the antennal teeth, and is usually apically spiniform, being subacute in one female (pre-spawning moult, CL $6.7 \mathrm{~mm}$ ). The submedian teeth on the carapace are absent in the male holotype but present in the three paratypes (minute in the male; small but distinct in the females). Variability in the presence of the submedian carapace teeth is unusual in Metacrangon; the absence of submedian teeth is otherwise known only for M. trigonorostris (Yokoya, 1933) (Komai, unpublished data).

\section{Distribution}

Known from northwest North Island, off Northland, and the Challenger Plateau; 1005-1074 m.

\section{Etymology}

From the Maori word "rau", meaning blade, in reference to the prominent, blade-like anterior mid-dorsal tooth of the carapace; used as a noun in apposition.

\section{Metacrangon teina sp. nov.}

(Figures 11-15)

\section{Material examined}

Holotype. Challenger Plateau, 39॰32.61' S, $169^{\circ} 42.87^{\prime}$ E, 636-634 m, beam trawl, TAN0707/93, 4 June 2007, female (CL 7.0 mm), NIWA 33204.

Paratypes. Challenger Plateau, same data as holotype, three females (CL 5.6-6.1 mm,

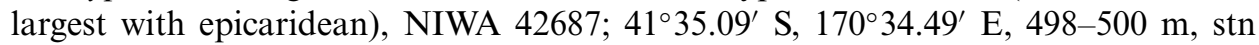
V0429, 11 September 1992, one female (CL $6.4 \mathrm{~mm}$ ), NIWA 11569; 42³4.00’ S, $170^{\circ} 19.90^{\prime}$ E, $600 \mathrm{~m}$, stn V0424, 9 September 1992, one male (CL $5.2 \mathrm{~mm}$ ), NIWA 11583; Foveaux Strait, 46³9.00' S, 16704.99’ E, 320-333 m, stn Z2378, 20 April 1971, one female (CL $7.3 \mathrm{~mm}$ ), NIWA 58582.

\section{Description}

Body (Figures 11, 12A,C) moderately robust. Rostrum (Figure 12A,B,D) dorsoventrally flattened, triangular with acute apex in dorsal view, directed forward, $0.20-0.25$ times as long as carapace; dorsal surface shallowly sulcate; lateral margin arched in lateral view, merging into orbital margin; midventral carina low, sharply delimited, ventral margin slightly sinuous in lateral view. Carapace (Figures 11, 12A) not widened posteriorly, distinctly longer than wide postorbitally; surface covered with very short setae; dorsal midline with two prominent teeth; anterior tooth relatively small for $M$. jacqueti species group, arising at midlength of rostrum, weakly to strongly ascending, overlapping rostrum, subequal to or distinctly larger than posterior (cardiac) tooth, tip reaching rostral apex; posterior (cardiac) tooth sometimes hooked, arising at $0.65-0.70$ of CL; submedian tooth relatively small; hepatic tooth relatively small, followed by clearly delimited epibranchial carina; antennal tooth 


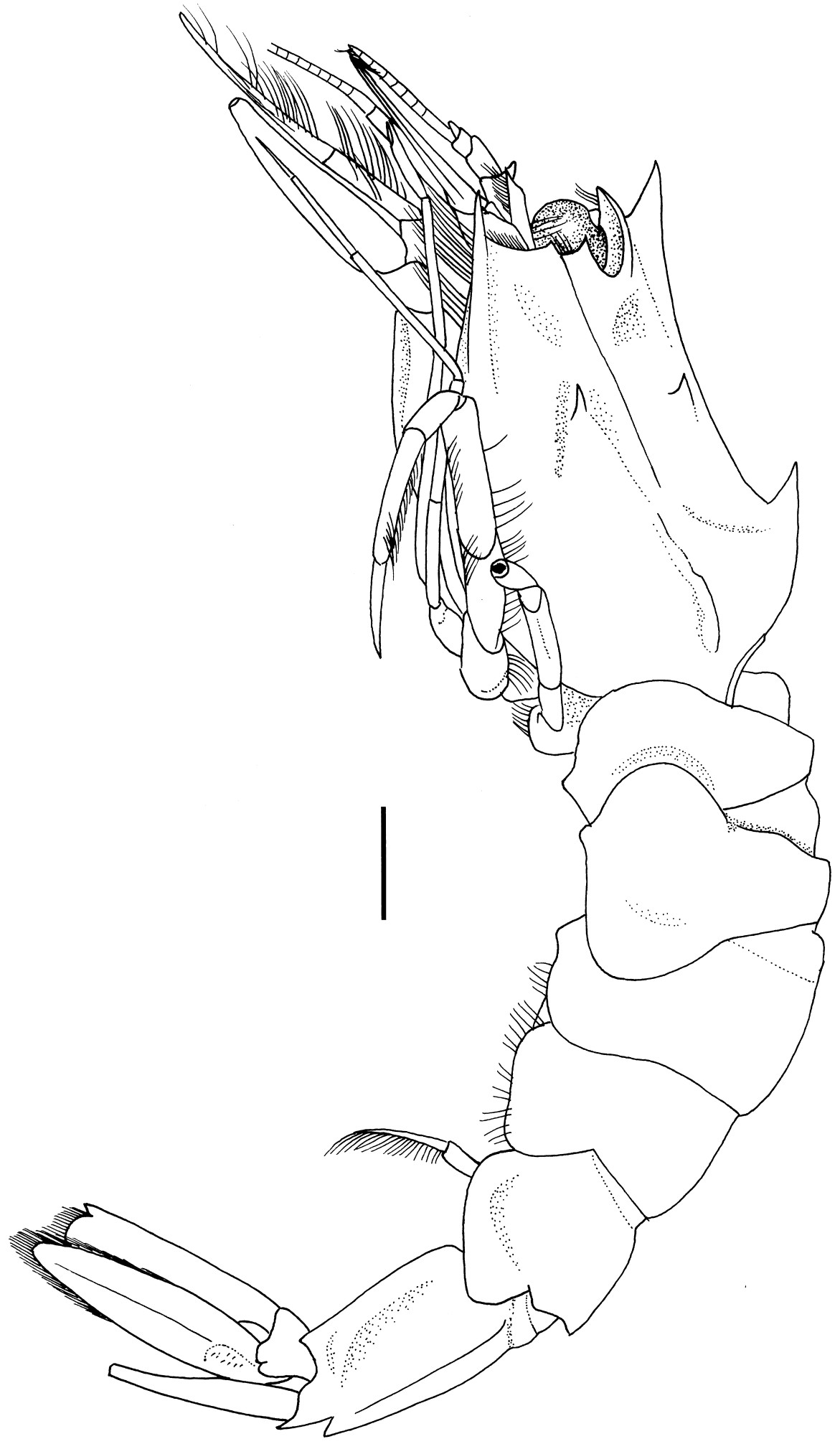


small, directed forward in dorsal view, slightly ascending in lateral view, acuminate, far falling short of rostral apex; orbital cleft absent; anterolateral margin between antennal and branchiostegal teeth concave, with tiny denticle inferior to base of antennal tooth; branchiostegal tooth moderately strong, directed slightly to somewhat laterally in dorsal view (Figures 12A, 15A) and slightly dorsally in lateral view, reaching beyond dorsodistal margin of antennal basicerite; pterygostomial tooth small, not visible in lateral view; postorbital carina obsolete, accompanied by longitudinal suture; epibranchial carina distinct.

Abdomen (Figures 11, 12C) barely sculptured; anterior two somites with trace of mid-dorsal carina anteriorly, third somite rounded or with faint trace of middorsal carina, and fourth somite with trace of mid-dorsal carina. First and second pleura each with blunt tooth medially on ventral margin; third pleuron with blunt tooth at anteroventral angle; fourth pleura unarmed. Fifth somite with low, but well delineated mid-dorsal carina; posterodorsal margin slightly produced medially; posterolateral margin unarmed; pleuron with posteroventral angle bluntly pointed or rounded; ventral margin slightly sinuous. Sixth somite with distinct, slightly curved submedian carinae, not reaching posterodorsal margin; dorsolateral carina distinct, reaching nearly to posterodorsal margin; posterodorsal margin produced, faintly bilobed; pleuron flared laterally, posteroventral tooth moderately strong, acute or subacute; posterolateral process strong, somewhat curved laterally, terminating in sharp tooth. Telson (Figure 14C) longer than sixth somite, gradually tapering posteriorly to acute apex; dorsal surface grooved mesially, with three pairs of dorsolateral spines, first pair located at about posterior 0.3 .

In spawning moults, thoracic sternum concave, armature absent; only fifth sternite with small tubercles medially; first to fourth abdominal sternites unarmed, fifth sternite with low median tubercle. In male and pre-spawning moults of females (Figure 14B), fifth thoracic sternite with sharp, procurved tooth; sixth to seventh somites each with rounded, strongly compressed prominence, becoming higher posteriorly; first to fourth abdominal sternites armed each with median tooth. Sixth abdominal sternite shallowly depressed medially.

Eye (Figure 12A,D) as long as wide or slightly wider than long; cornea as wide as eyestalk, light brown or opaque in preservative, corneal width $0.20-0.25$ of CL; eyestalk with small, papilla-like dorsal tubercle.

Antennular peduncle (Figure 12A,D) relatively stout, slightly falling short of midlength of antennal scale. First segment with prominent, bluntly pointed distolateral process directed dorsally; distomesial margin unarmed; stylocerite nearly reaching distolateral process, acutely pointed, lateral margin gently convex. Second segment distinctly widened distally, with prominent, blunt distolateral process. Third segment much wider than long. Outer flagellum slightly over-reaching distal margin of lamella of antennal scale, consisting of 9 or 10 articles in females (in male specimen, flagella broken off).

Antennal basicerite (Figure 12A,D) stout, with sharply pointed dorsodistal lateral angle and short ventrolateral tooth slightly over-reaching dorsodistal lateral angle; carpocerite subcylindrical, reaching distal 0.20 of antennal scale. Antennal scale about

Figure 11. Metacrangon teina sp. nov., holotype, female (CL 7.0 mm), NIWA 33204. Entire animal in lateral view. Scale bar: $2 \mathrm{~mm}$. 


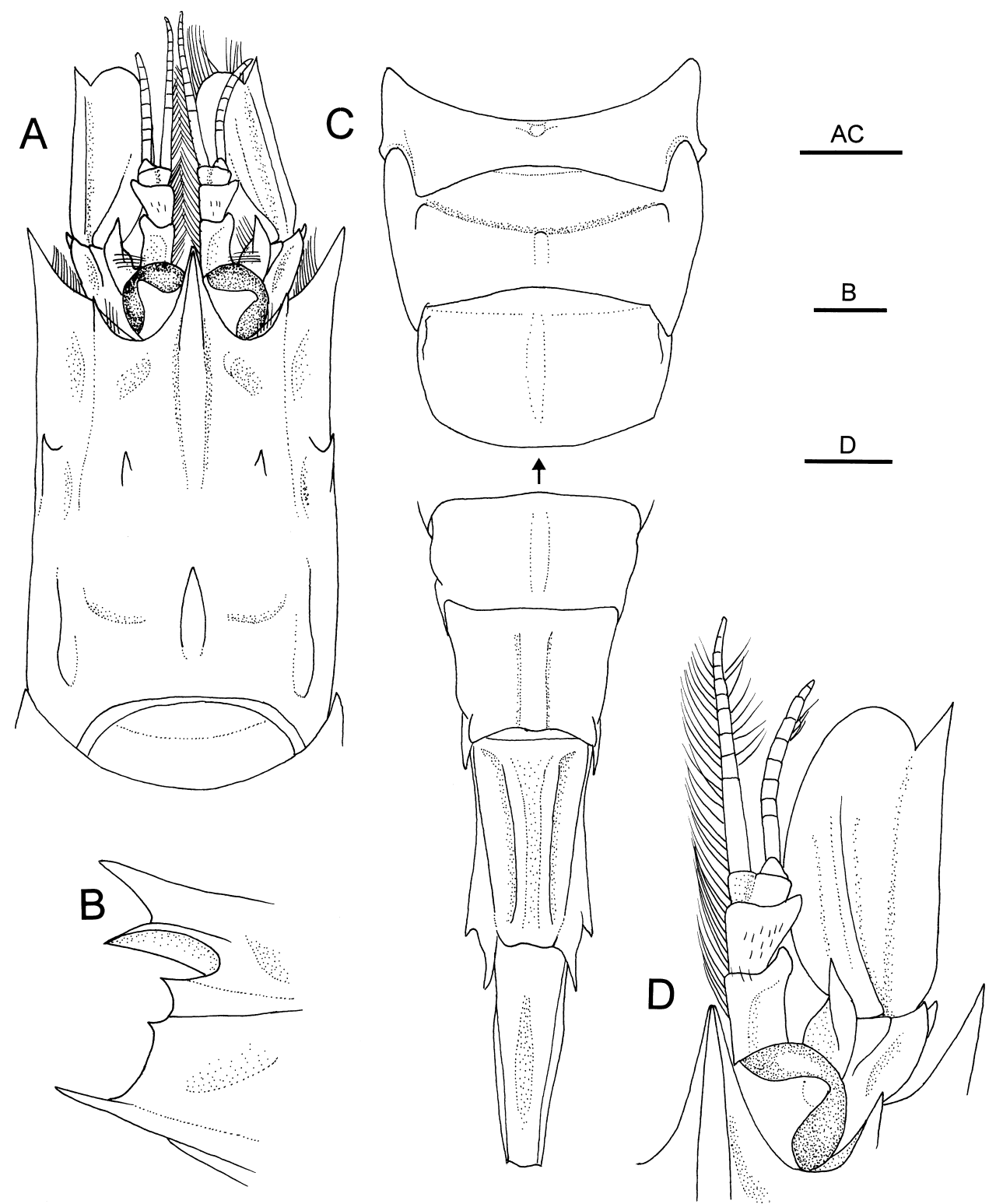

Figure 12. Metacrangon teina sp. nov., holotype, female (CL $7.0 \mathrm{~mm}$ ), NIWA 33204. (A) Carapace and cephalic appendages, dorsal view (setae partially omitted); (B) anterior part of carapace, lateral view (setae omitted); (C) abdomen, dorsal view (telson damaged; setae omitted); (D) right side of anterior part of carapace, eye and antennae, dorsal view (setae partially omitted). Scale bars: $2 \mathrm{~mm}$ for A, C; $1 \mathrm{~mm}$ for B, D.

0.50 times as long as carapace and 2.0 times longer than wide; lateral margin nearly straight; distolateral tooth moderately wide, slightly over-reaching rounded distal margin of lamella. 

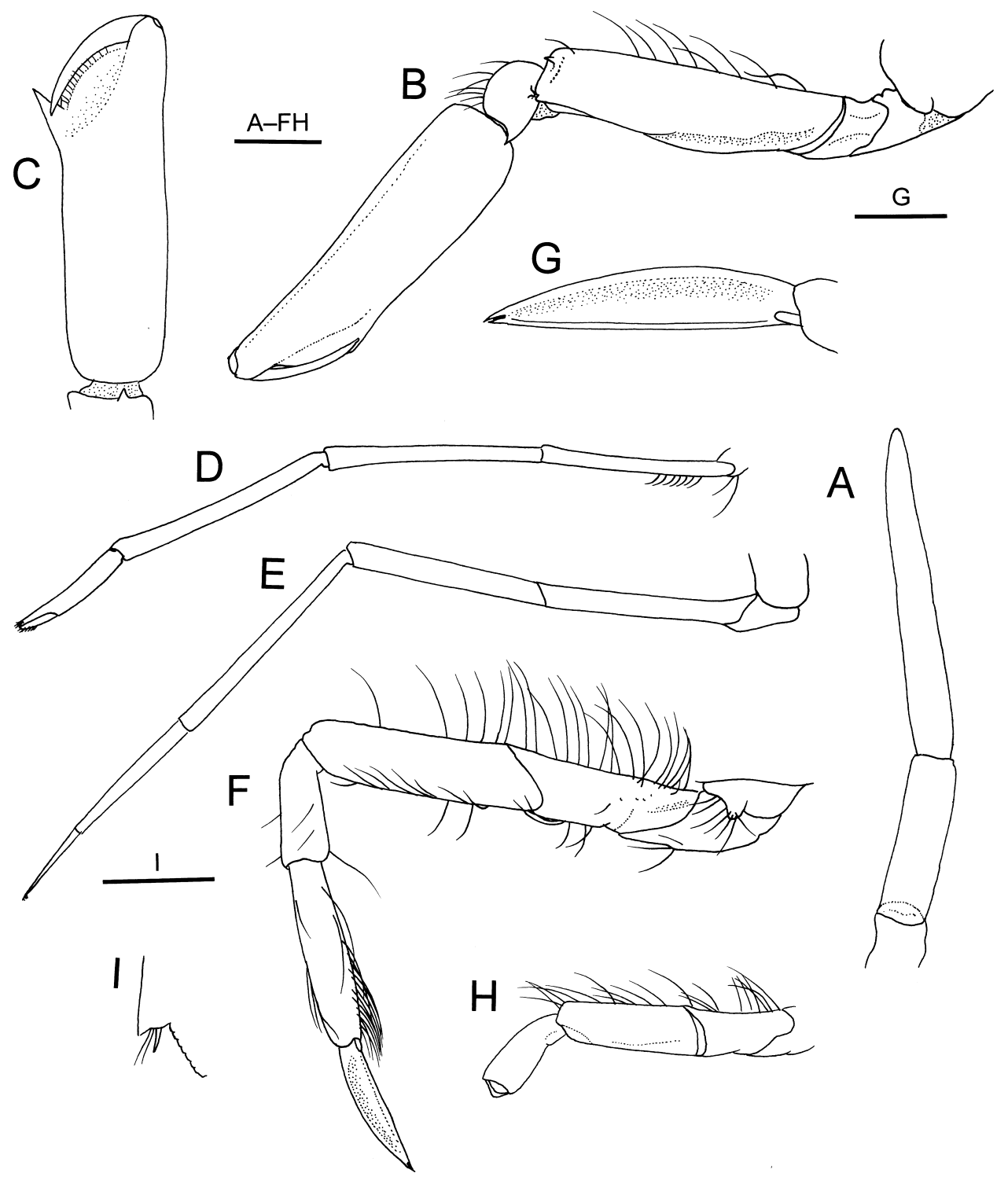

Figure 13. Metacrangon teina sp. nov., holotype, female (CL $7.0 \mathrm{~mm}$ ), NIWA 33204. Left appendages. (A) Distal two segments of third maxilliped, ventral (flexor) view; (B) first pereopod, lateral view; (C) same, subchela, ventral (flexor) view; (D) second pereopod, lateral view; (E) third pereopod, lateral view; (F) fourth pereopod, lateral view; (G) same, dactylus, flexor view; $(\mathrm{H})$ fifth pereopod (dactylus and propodus missing); (I) posterolateral part of uropodal exopod. Scale bars: $1 \mathrm{~mm}$ for A-F, H; $0.5 \mathrm{~mm}$ for $\mathrm{G}$, I.

Third maxilliped relatively slender, over-reaching antennal scale by 0.6 length of ultimate segment; margins and dorsal surface of distal two segments with numerous short to long setae; ultimate segment (Figure 13A) gradually tapering distally, 7.58.0 times longer than wide; penultimate segment about 3.5 times longer than wide; 


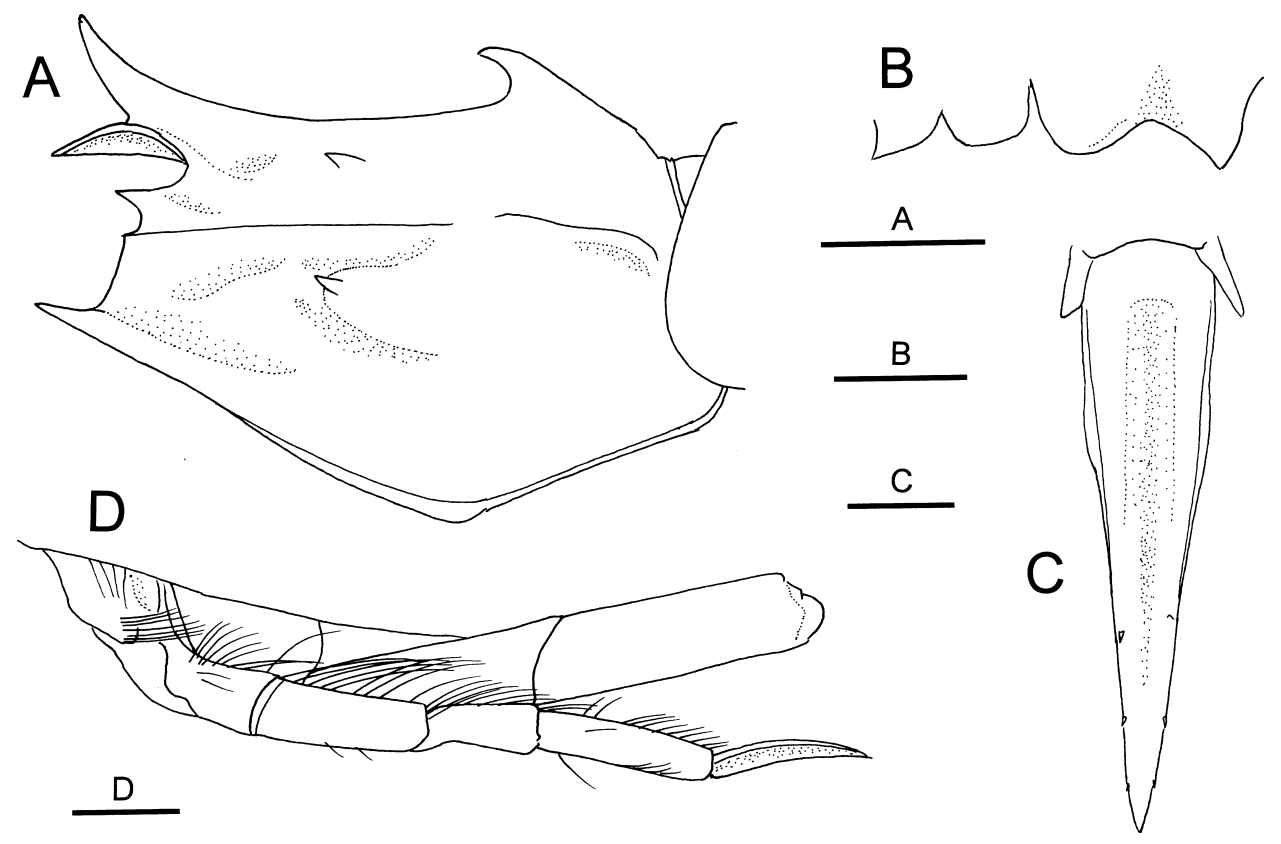

Figure 14. Metacrangon teina sp. nov., paratype, female (CL $5.8 \mathrm{~mm}$ ), NIWA 42687. (A) Carapace, lateral view; (B) armature of fifth to eighth thoracic sternites, left ventrolateral view; (C) telson, dorsal view; (D) merus and ischium of fourth pereopod and entire fifth pereopod, right side, lateral view. Scale bars: $2 \mathrm{~mm}$ for A; $1 \mathrm{~mm}$ for B-D.

antepenultimate segment sinuously curved in dorsal view, with thick tuft of long setae dorsodistally; ventral surface unarmed; exopod far falling short of distal margin of antepenultimate segment, with well-developed flagellum.

First pereopod (Figure 13B,C) moderately stout, reaching distal margin of antennal scale; palm 3.5-3.7 times longer than wide, not widened proximally or distally, cutting edge oblique; lateral and mesial margins nearly straight; thumb moderately broad; carpus with small ventrolateral tooth, otherwise unarmed on lateral margin; merus with one small dorsodistal tooth, ventral margin sinuous, crested. Second pereopod (Figure 13D) chelate, reaching nearly to midlength of antennal scale; dactylus about 0.5 times as long as palm; cutting edges of fingers minutely pectinate; length ratio of chela to ischium $1: 1.8: 1.7: 1.4$; coxa with prominent flap-like process (not figured). Third pereopod (Figure 13E) slender, nearly reaching distal margin of antennal scale by tip of dactylus; length ratio of dactylus to ischium $1: 1.7: 2.8: 2.2: 2.5$. Fourth pereopod (Figure 12F) moderately stout, slightly over-reaching midlength of antennal scale by dactylus; dactylus (Figure 13G) narrowly spatulate, about 0.8 times as long as propodus, margins naked; dactylus-propodus articulation about $45^{\circ}$; propodus about 4.2 times longer than wide, bearing row of stiff setae on dorsal and ventral margins; carpus shorter than propodus, with sparse setae on dorsal margin; merus with faint ridge on lateral surface; ischium slightly shorter than merus; row of long setae on dorsal and ventral margins of merus and ischium (dorsal setae longer than ventral setae). Fifth pereopod (Figures 13H, 14D) distinctly shorter than fourth 

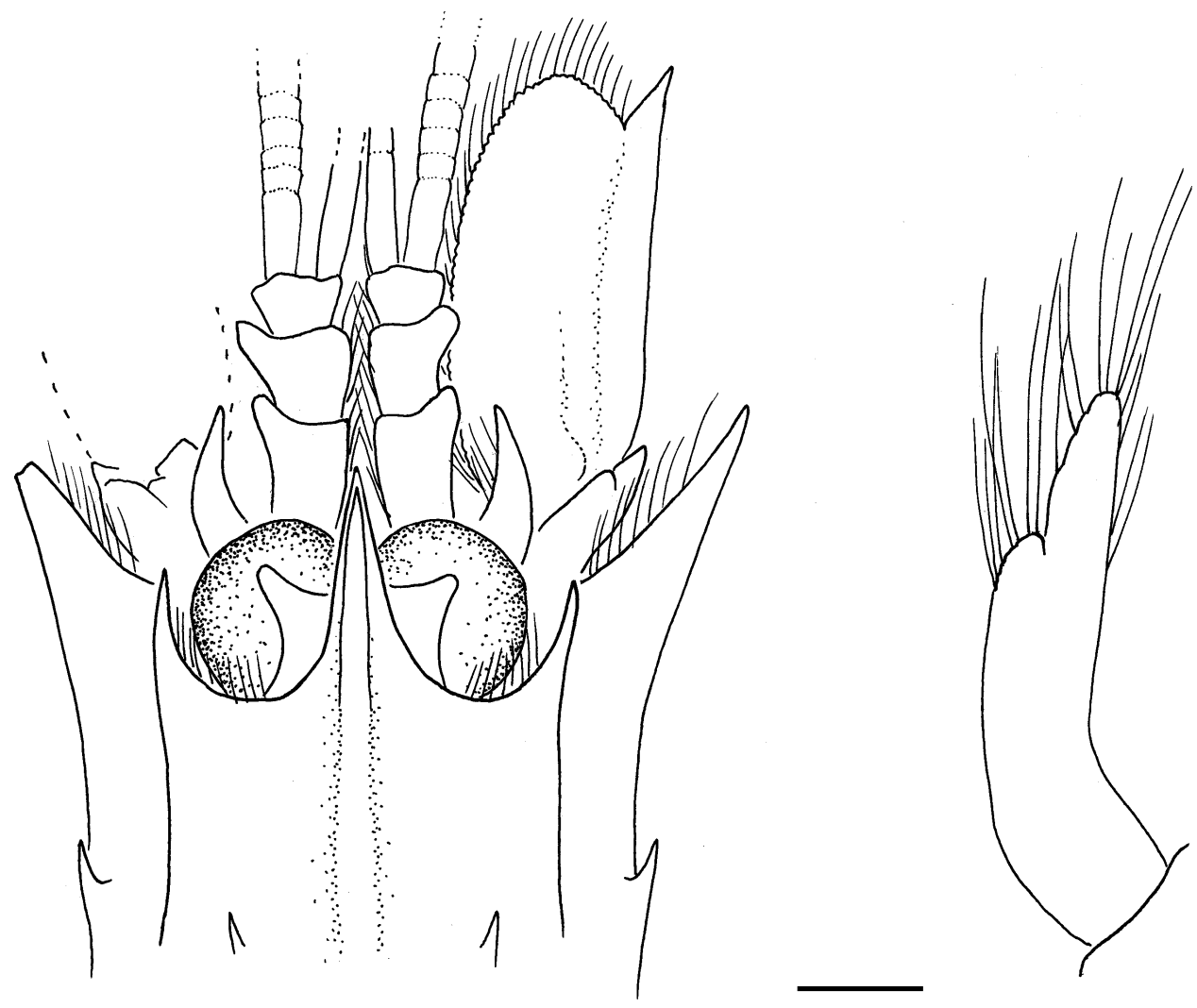

Figure 15. Metacrangon teina sp. nov., paratype, male (CL $5.2 \mathrm{~mm}$ ), NIWA 11583. (A) Anterior part of carapace and cephalic appendages, dorsal view (left branchiostegal tooth, antennular flagella and left antennal scale broken off); (B) endopod of left second pleopod. Scale bar: $1 \mathrm{~mm}$ for A, $0.25 \mathrm{~mm}$ for B.

pereopod, falling short of base of branchiostegal tooth or only slightly over-reaching distal margin of merus of fourth pereopod; dactylus subspatulate, but more slender than that of fourth pereopod, about 0.9 times as long as propodus; setation much less than in fourth pereopod.

Male second pleopod with appendix masculina short, bearing several setae.

Uropod not reaching tip of telson; exopod with nearly straight lateral margin, posterolateral tooth acute (Figure 13I); minute spinule mesial to posterolateral tooth; endopod longer and narrower than exopod.

\section{Colouration in life}

Not known.

Size

Largest female at spawning moult, CL $7.3 \mathrm{~mm}$; only known male CL $5.2 \mathrm{~mm}$. 


\section{Distribution}

Known only from New Zealand: Challenger Plateau, at depths of 498-636 m; Foveaux Strait, 320-333 m.

\section{Etymology}

Named after the Maori word "teina", meaning younger brother or sister, in reference to the close relationship to $M$. knoxi; used as a noun in apposition.

\section{Metacrangon knoxi (Yaldwyn, 1960)}

(Figure 16)

Sclerocrangon n. sp. - Richardson and Yaldwyn 1958, p. 40, fig. 43.

Sclerocrangon knoxi - Yaldwyn 1960, p. 35, fig. 7 [type locality: Chatham Rise].

Metacrangon knoxi - Zarenkov 1965, p. 1764; Crosnier and Forest 1973, p. 238; Komai 1997, p. 670, figs 1E, 8.

\section{Material examined}

Paratypes. Chatham Rise, $44^{\circ} 04^{\prime} \mathrm{S}, 178^{\circ} 04^{\prime} \mathrm{W}, 468 \mathrm{~m}$, Chatham Islands 1854 Expedition, stn 52, 10 February 1954, seven females (CL 6.8-10.8 mm), two males (CL 7.0, $8.3 \mathrm{~mm}$ ), CM AQ1228.

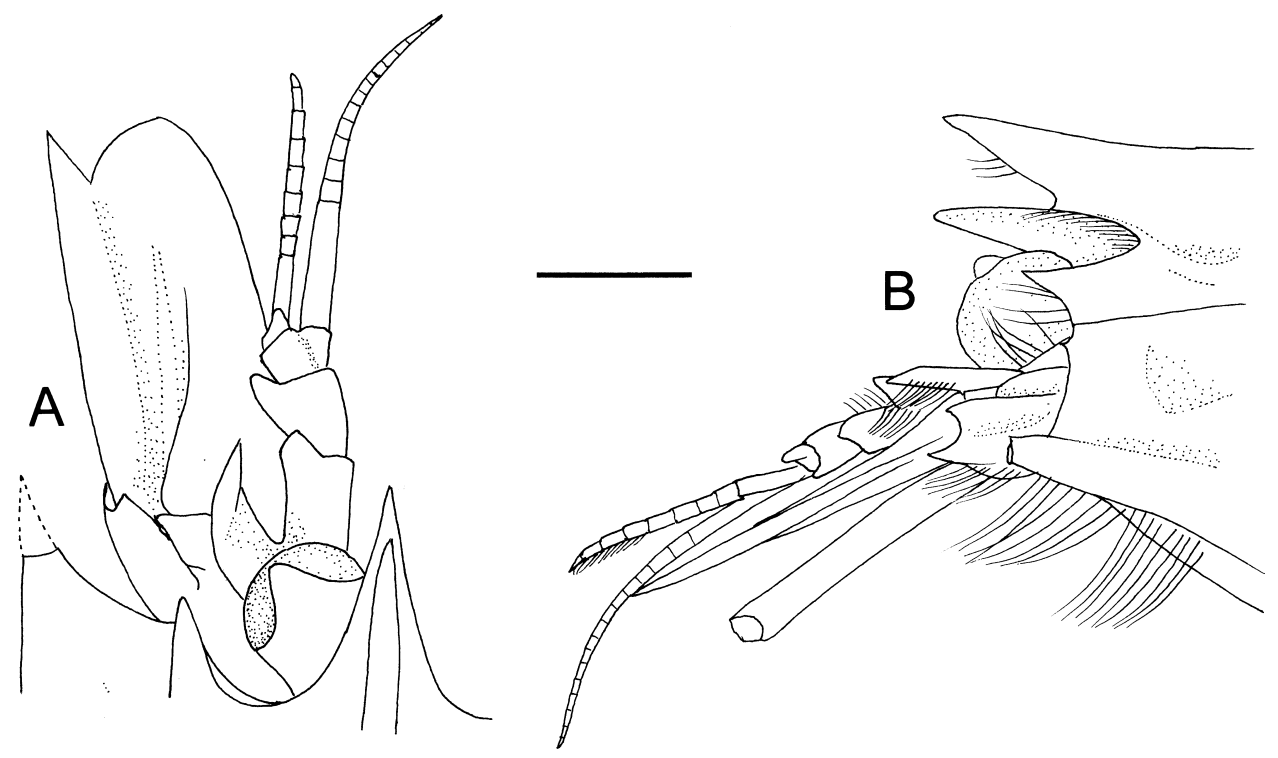

Figure 16. Metacrangon knoxi (Yaldwyn, 1960), paratype, female (CL $10.8 \mathrm{~mm}$ ), CM AQ1228. (A) Anterior part of carapace (left side) and left cephalic appendages, dorsal view; (B) same, lateral view. Scale bar: $2 \mathrm{~mm}$. 


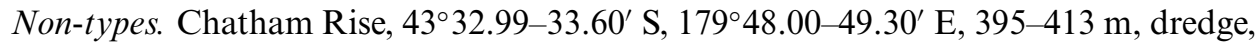
stn 868, 18 December 1976, one female (CL 9.5 mm), NIWA 58583; 4337.71-37.89’ S, 178 36.64-36.67' W, 420-426 m, beam trawl, TAN0705/185, 18 April 2007, one ovigerous female (CL $9.8 \mathrm{~mm}$; egg diameter $1.85 \mathrm{~mm}$ ), NIWA 42662; 43⒛12' S, $178^{\circ} 58.88^{\prime}$ E, $418 \mathrm{~m}$, stn V0372, 13 September 1989, one female (CL $9.4 \mathrm{~mm}$ ), NIWA 58584; 4407.87-08.11’ S, 17450.67-50.64’ E, 516-518 m, TAN0705/25, 4 May 2007, two ovigerous females (CL 10.0-10.3 mm), NIWA 33007; 4358.8-59.04' S, 179³7.8937.45' E, 531-532 m, TAN0705/84, 9 May 2007, two females (CL 9.9-10.0 mm),

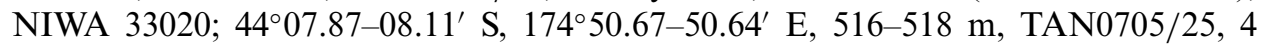
May 2007, one male (CL $5.8 \mathrm{~mm}$ ), one ovigerous female (CL $10.3 \mathrm{~mm}$ ), NIWA 33004; $43^{\circ} 49.95-49.60^{\prime} \mathrm{S}, 176^{\circ} 42.82-42.33^{\prime} \mathrm{E}, 477-479 \mathrm{~m}$, TAN0705/34, 5 May 2007, one female (CL $7.4 \mathrm{~mm}$ ), NIWA 33008.

Size

Largest female CL 10. 3 mm, ovigerous females CL 9.8-10.3 m; male CL 5.8 mm.

\section{Remarks}

Komai (1997) gave a diagnosis of this species based on an examination of the paratypes, but the following diagnostic details could be added: rostral tip acutely pointed in dorsal view (Figure 16A), lateral margin nearly straight in lateral view (Figure 16B); eye about as long as wide, with rounded dorsal tubercle on eyestalk (Figure 16A,B); dorsolateral distal angle of antennal basicerite sharply pointed (Figure 16A,B).

The present specimens constitute additional records of Metacrangon knoxi for the Chatham Rise and slightly extend the known bathymetric range. Despite widespread sampling around New Zealand in the five decades since $M$. knoxi was first described, no specimens of the species have been found beyond the Chatham Rise, suggesting that the species might be locally endemic.

\section{Distribution}

Presently known only from the Chatham Rise; 395-532 m.

Metacrangon richardsoni (Yaldwyn, 1960)

(Figures 17, 18)

Sclerocrangon n. sp. - Richardson and Yaldwyn 1958, p 40, fig. 42.

Sclerocrangon richardsoni - Yaldwyn, 1960, p. 39, fig. 8 [type locality: Palliser Bay, Cook Strait, $\left.41^{\circ} 42.5^{\prime} \mathrm{S}, 175^{\circ} 09^{\prime} \mathrm{E}, 1007 \mathrm{~m}\right]$.

\section{Material examined}

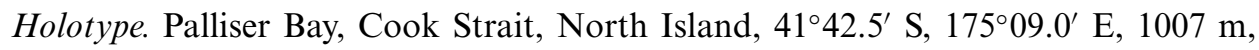
mud with shell, rock and gravel, VUZ83, beam trawl, 17 February 1957, CL $8.9 \mathrm{~mm}$ (10.1 mm including rostrum), NMZ Cr000782. 

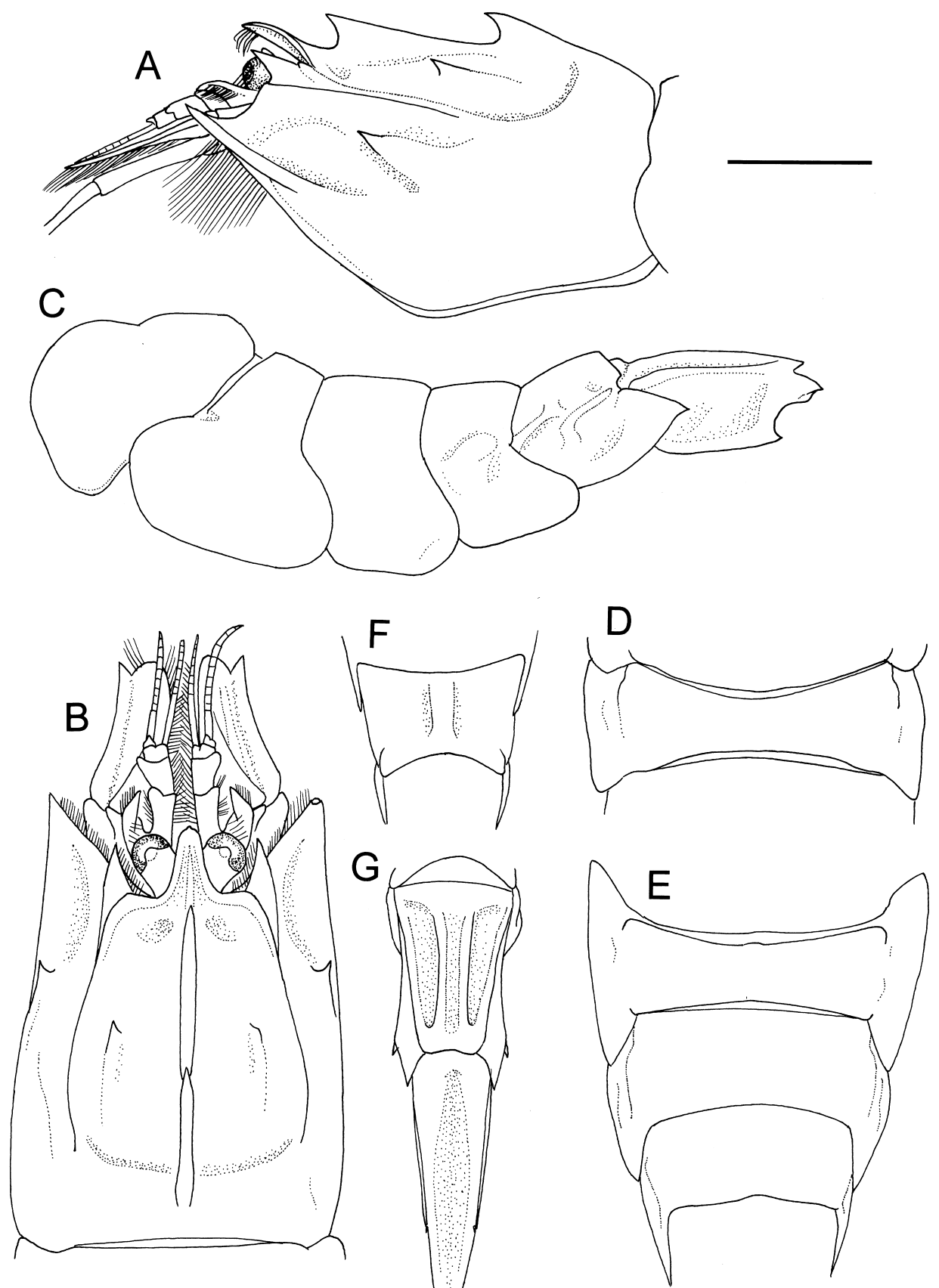

Figure 17. Metacrangon richardsoni (Yaldwyn, 1960), female (CL 11.8 mm), NIWA 29392. (A) Carapace and cephalic appendages, lateral view; (B) same, dorsal view (setae partially omitted); (C) abdomen, lateral view; (D) first abdominal somite, dorsal view; (E) second to fourth abdominal somites, dorsal view; (F) fifth abdominal somite, dorsal view; (G) sixth abdominal somite and telson, dorsal view (tip of telson broken off). Scale bar: $5 \mathrm{~mm}$. 

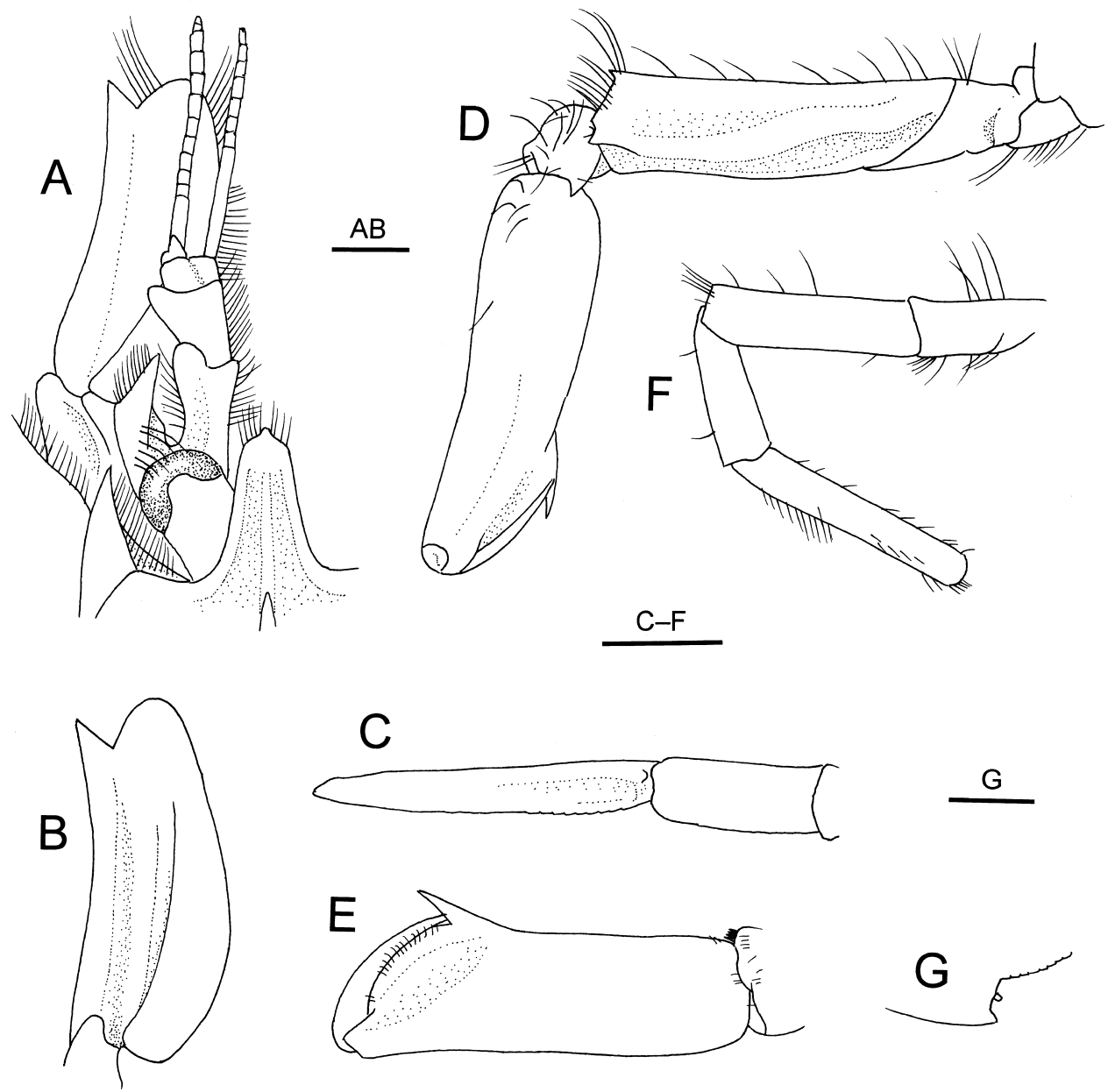

Figure 18. Metacrangon richardsoni (Yaldwyn, 1960), female (CL $11.8 \mathrm{~mm}$ ), NIWA 29392. (A) Rostrum, left eye and antennae, dorsal view; (B) left antennal scale, dorsal view (setae omitted); (C) distal two segments of left third maxilliped, ventral (flexor) view; (D) left first pereopod, lateral view; (E) same, subchela, dorsal (extensor) view; (F) left fifth pereopod (dactylus missing), lateral view; (G) posterolateral part of left uropodal exopod, dorsal view (setae omitted). Scale bars: $2 \mathrm{~mm}$ for $\mathrm{C}-\mathrm{F} ; 1 \mathrm{~mm}$ for $\mathrm{A}, \mathrm{B} ; 0.5 \mathrm{~mm}$ for $\mathrm{G}$.

Non-type. Hikurangi Margin, Waiarapa Seep (North Tower), TAN0616/79, 41 ${ }^{\circ} 46.95-$ 46.83' S, 175'23.98-24.25' E, 1040-1053 m, RV Tangaroa, 13 November 2006, one female (CL $11.8 \mathrm{~mm}$ ), NIWA 29392.

\section{Abbreviated description}

Body (Figure 17) robust. Rostrum (Figures 17A,B, 18A) somewhat ascending, narrowing anteriorly; distal margin generally rounded, with minute point terminally; dorsal surface faintly carinate on midline; lateral margin gently arched in lateral view, continuing to postorbital carina; midventral carina relatively row, ventral margin nearly 
straight. Carapace (Figure 17A,B) slightly longer than wide postorbitally; orbital margin with distinct cleft; anterior mid-dorsal tooth relatively large, compressed laterally, epigastric in position, arising at 0.10 of CL; posterior mid-dorsal tooth subequal in size to anterior mid-dorsal tooth, arising at 0.53 of CL; submedian and hepatic teeth moderately small; antennal tooth acuminate, slightly falling short of level of rostral apex, directed forward in dorsal view, slightly ascending in lateral view; branchiostegal tooth moderately strong, directed forward in lateral view, slightly ascending in lateral view; no denticle on anterolateral margin between antennal and branchiostegal teeth; postorbital carina low, blunt; epibranchial carina absent.

First to fourth abdominal somites rounded dorsally, fifth somite with broad, clearly delimited mid-dorsal carina (Figure 17D-F). First to third abdominal pleura rounded marginally, posteroventral margin of fourth pleuron rounded, that of fifth pleuron with acute posteroventral tooth. Sixth abdominal somite (Figure 17G) with distinct submedian and dorsolateral carinae.

Eye (Figures 17B, 18A) slightly longer than wide; cornea darkly pigmented, as wide as eyestalk, corneal width 0.12 of CL; eyestalk with papilla-like dorsal tubercle. Antennular peduncle (Figures 17B, 18A) moderately stout, reaching midlength of antennal scale; first segment with prominent, blunt distolateral process, distomesial margin unarmed; stylocerite directed slightly mesially in dorsal view and directed forward in lateral view, terminating in acute tooth, reaching tip of distolateral process of first segment, lateral margin strongly convex; second segment with blunt distolateral process; outer flagellum consisting of 12 articles. Antennal basicerite (Figures $17 \mathrm{~B}, 18 \mathrm{~A}$ ) with rounded dorsodistal lateral angle; antenna scale 0.45 times as long as carapace, about 2.4 times longer than wide; lateral margin concave; distolateral tooth moderately slender, reaching distal margin of roundly triangular distal lamella.

Third maxilliped relatively slender; ultimate segment (Figure 18C) about 6.2 times longer than wide, penultimate segment about 2.6 times longer than wide; antepenultimate segment with pair of greatly unequal, movable spinules subdistally on ventral surface. First pereopod (Figure 18D,E) moderately stout; palm about 3.5 times longer than wide; carpus with small ventrolateral tooth; merus with small dorsodistal tooth. Fifth pereopod as illustrated (Figure 18F).

Uropodal exopod with minute posterolateral tooth and minute movable spinule just mesial to it (Figure 18G).

\section{Colouration}

Colour in life was described by Yaldwyn (1960).

\section{Size}

The non-ovigerous female holotype, CL $8.5 \mathrm{~mm}$; the second female specimen is a spawning moult, CL $11.8 \mathrm{~mm}$.

\section{Distribution}

Known only from the southern South Island, New Zealand, from type locality in Cook Strait and from the Wairarapa Seep, the Hikurangi Margin; 1007-1053 m. 


\section{Remarks}

The present specimen, representing the second of this very rare species, agrees well with the holotype in every diagnostic aspect, and is the first record of the genus from a chemosynthetic environment.

As Yaldwyn (1960) noted, M. richardsoni is morphologically very similar to M. munita (Dana, 1851) from the northeastern Pacific. Komai (1995) pointed out that M. laevis (Yokoya, 1933) also shows substantial similarity to M. richardsoni. Differences among these three species were discussed in detail by Komai (1995).

\section{Discussion}

The four new species described in this study are all referable to the M. jacqueti species group in having a strong anterior mid-dorsal tooth on the carapace, which arises around the rostral base and overlaps the rostrum, and the presence of ventral tooth on the pleura of the anterior three abdominal somites (Komai 1997). Furthermore, the lack of the orbital cleft and the non-setose dactyli of the fourth and fifth pereopods link these four new species to $M$. knoxi known only from the Chatham Rise, off New Zealand. In other species of the M. jacqueti group, the orbital margin has a distinct cleft that corresponds to a cross-point with the postorbital carina; and the dactyli of the fourth and fifth pereopods have stiff setae on the margins (Komai 1997). In particular, the lack of the orbital cleft is presumably autapomorphic, because other species of Metacrangon, as well as other allied genera such as Argis Krøyer, 1842, Crangon Fabricius, 1798, Mesocrangon Zarenkov, 1965, Neocrangon Zarenkov, 1965, Notocrangon Coutière, 1900, Rhynocrangon Zarenkov, 1965 and Sclerocrangon Sars, 1883, all have the orbital cleft (Komai, unpublished data). It is possible that these five species distributed in the rather limited geographical range form a monophyletic assemblage.

Differentiating characters among the five species are summarized in Table 1. Metacrangon haona sp. nov. and M. teina sp. nov. appear closest to $M$. knoxi in the anterior mid-dorsal tooth arising anterior to the rostral base, a character uniquely shared by these three species. However, M. haona is distinctive even in the genus in its unusually elongate rostrum, the presence of a lateral tooth on the posterodorsal margin of the fifth abdominal somite, bi-toothed posterodorsal margin of the sixth abdominal somite, and spiniform dorsal tubercle on the eyestalk. Furthermore, the very strong, upturned anterior mid-dorsal tooth and strongly curved branchiostegal tooth seem to be a characteristic of M. haona, although these characters may be sexually variable. The distinct mid-dorsal carina on the carapace distinguishes $M$. haona sp. nov. and $M$. knoxi from $M$. teina sp. nov. In the latter, the mid-dorsal carina on the first to fourth somites is obsolete. Metacrangon teina sp. nov. further differs from $M$. knoxi in the arched, rather than straight, lateral margin of the rostrum.

Metacrangon hikurangi sp. nov. and $M$. rau differ from the other three species in the posterostral position of the anterior mid-dorsal tooth of the carapace. Metacrangon hikurangi is unique among the five allied species in the distally rounded rostrum and the lack of dorsolateral spines on the telson. In the other four species, the rostral tip is acuminate and the telson bears three pairs of dorsolateral spines. Metacrangon rau sp. nov. is unique among the five species in having the posterior mid-dorsal tooth arising at about the midlength of the carapace, rather than at $0.6-0.7$ length in the other four 


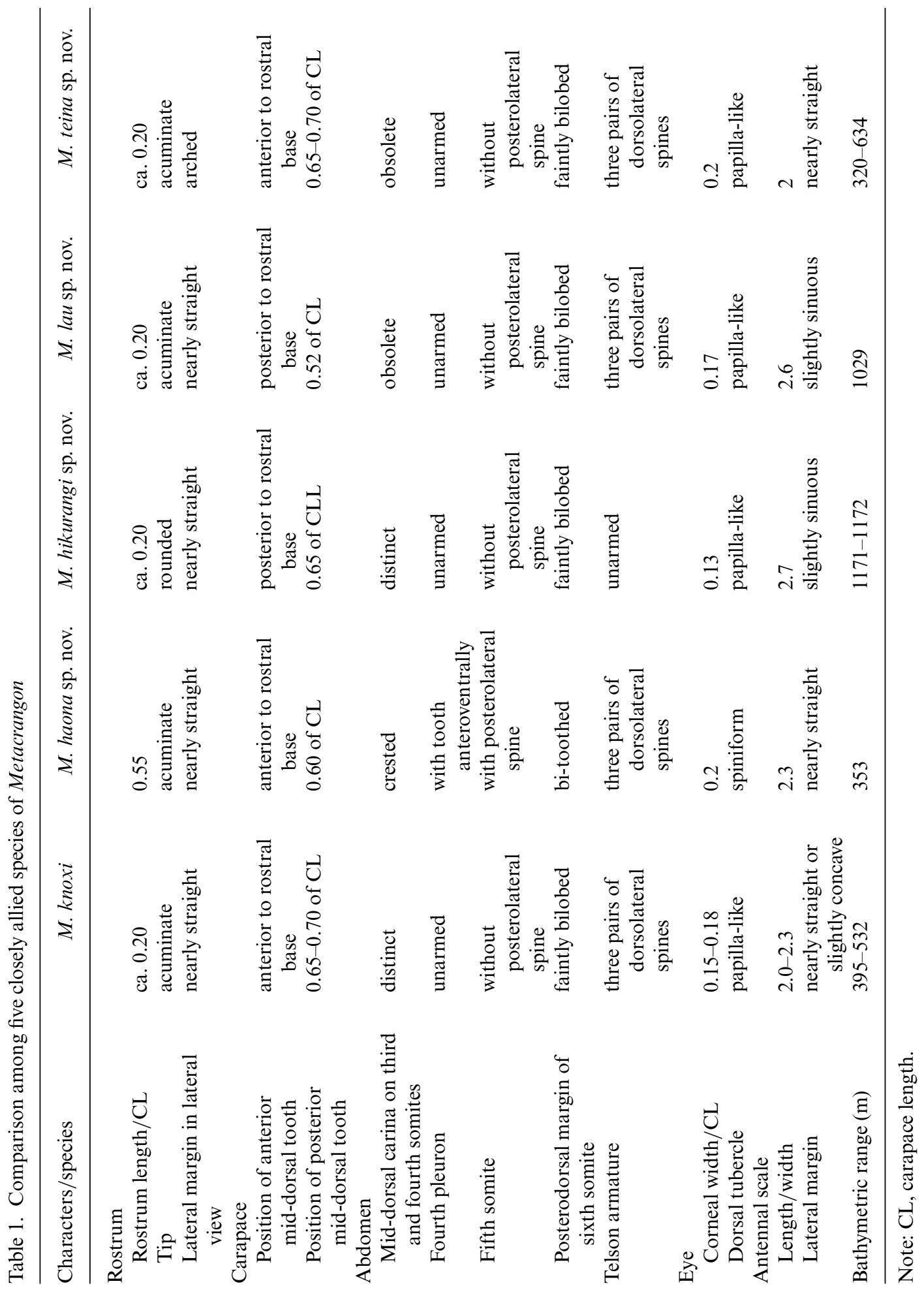




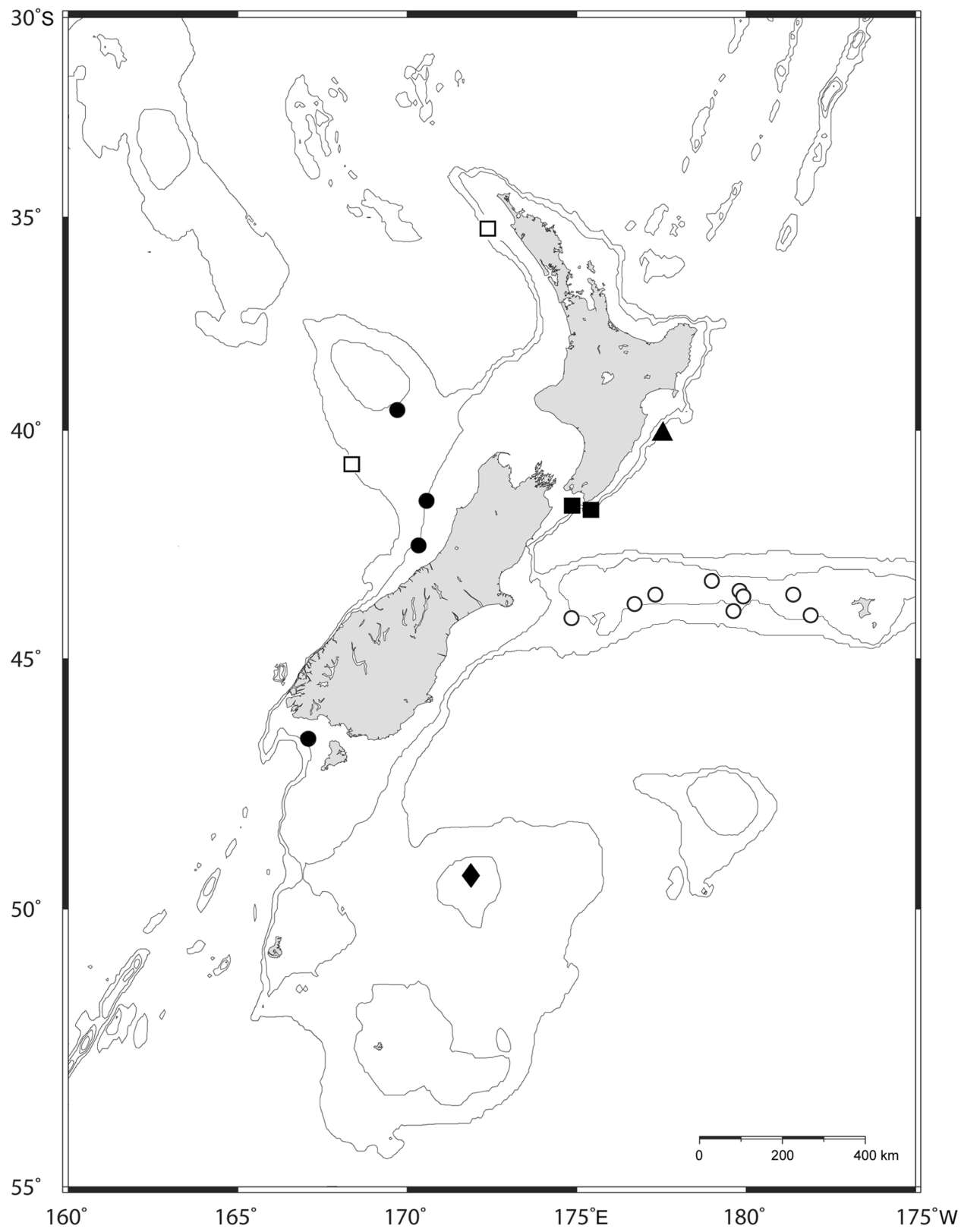

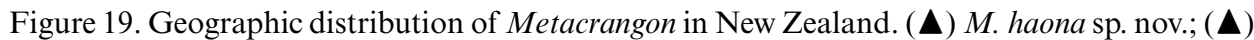

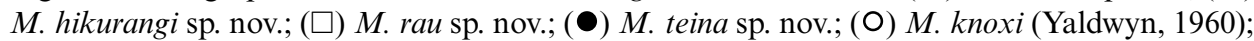
(ロ) M. richardsoni (Yaldwyn, 1960). Position data from present study and Yaldwyn (1960).

species. Furthermore, the anterior mid-dorsal tooth is considerably larger than in the other four species.

As discussed by Komai (1997), species of the M. jacqueti group are scattered across the world oceans and have rather narrow geographical ranges, respectively; all species 
are deep-water inhabitants. Since Komai (1997), M. bahamondei was described from southern Chile and represents the southernmost record of the genus, as well as the species group. Now, this species group contains 13 species, of which seven species $(54 \%)$ are distributed in the southern hemisphere.

It is remarkable that there are six species of Metacrangon in New Zealand waters, accounting for $67 \%$ of species known from the southern hemisphere. None of the six have been recorded outside New Zealand waters, strongly suggesting that these species are endemic there. Three species, $M$. hikurangi sp. nov., $M$. rau sp. nov. and $M$. richardsoni, were recorded at depths greater than $1000 \mathrm{~m}$, whereas the other species occur in water shallower than $650 \mathrm{~m}$, suggesting also the possibility of bathymetric isolation. With only limited records, it is not yet known if these six species are sympatric. Each species appears to be geographically isolated except for possibly $M$. rau sp. nov. and $M$. teina sp. nov., although these two species do not overlap bathymetrically (Figure 19 Table 1). Species of Metacrangon are known to have large and few eggs (Fujino and Miyake 1970; Komai 1995). In fact, Fujino and Miyake (1970) reported the latestage embryo that clearly suggests that hatching occurs at a late stage of development. This provides circumstantial evidence for limited dispersal capabilities of species of the genus.

\section{Acknowledgements}

S.T.A. gratefully acknowledges support from the Foundation for Research, Science and Technology (FRST) (contract C01X0502) and the NIWA Capability Fund. We are also grateful to Kareen Schnabel (NIWA) and Rick Webber (MNZ) for access to the collections under their care. Most specimens were collected by NIWA under various research programmes, most notably "Seamounts: their importance to fisheries and marine ecosystems" (FRST contracts C01X0028, C01X0224), "New Zeeps 06" (cruise TAN0616), "New Vents" (cruise SO1913, German Federal Ministry for Education and Research), and Oceans Survey 2020 jointly funded by NIWA, the Department of Conservation, Land Information New Zealand, and the New Zealand Ministry of Fisheries (ZBD200701).

\section{References}

Butler TH. 1980. Shrimps of the Pacific coast of Canada. Can Bull Fisheries Aquatic Sci. 202: $1-280$.

Crosnier A, Forest J. 1973. Les crevettes profondes de l'Atlatinque oriental tropical. Faune Tropic. 19:1-409.

Fujino T, Miyake S. 1970. Caridean and stenopodidean shrimps from the East China and Yellow Seas (Crustacea: Decapoda: Natantia). J Fac Agric Kyushu Univ. 16:237-312.

Kim JN. 2005. Two new crangonid shrimps of the genus Metacrangon (Decapoda, Caridea) from Japan. J Crustacean Biol. 25:242-250.

Kim JN, Hayashi K. 2003. Syncrangon, a new crangonid genus, with redescription of S. angusticauda (De Haan) and S. dentata (Balss) (Crustacea, Decapoda, Caridea) from East Asian waters. Zool Sci. 20:669-682.

Komai T. 1994. [Taxonomic synopsis of Caridea (Pandalidae, Hippolytidae, Crangonidae) occurring on continental shelf the Sea of Japan. Contrib Fisheries Resource Jpn Sea Block. 31:81-107 [in Japanese].

Komai T. 1995. Redescription of a little known crangonid shrimp, Metacrangon laevis (Yokoya, 1933) (Decapoda, Caridea, Crangonidae) from Hokkaido, Japan. Crustaceana 68: 893-903. 
Komai T. 1997. A review of the Metacrangon jacqueti group, with descriptions of two new species (Decapoda, Caridea, Crangonidae). Zoosystema 19:651-681.

Komai T, Komatsu H. 2009. Deep-Sea shrimps and lobsters (Crustacea: Decapoda: Penaeidea, Caridea, Polychelidea) from northern Japan, collected during the Project "Research on Deep-sea Fauna and Pollutants off Pacific Coast of Northern Honshu, Japan, 2005-2008." Nat Mus Nature Sci Monogr. 39: 495-580.

Komai T, Taylor J. Three new species of the crangonid genus Metacrangon Zarenkov (Crustacea: Decapoda: Caridea) from Australia. Mem Mus Vict. 67: in press.

Poore GCB, McCallum AW, Taylor J. 2008. Decapod Crustacea of the continental margin of southwestern and central Western Australia: preliminary identifications of 524 species from FRV Southern Surveyor voyage SS10-2005. Mus Victoria Sci Rep. 11: 1-106.

Retamal M, Gorny M. 2003. Revisión del género Metacrangon y descripción de una nueva especie (Decapoda, Crangonidae). Invest Marinas Valparaíso. 31: 85-90.

Richardson JR, Yaldwyn JC. 1958. A guide to the natant decapod Crustacea (shrimp and prawns) of New Zealand. Tuatara 7:17-41.

Stebbing TRR. 1914. South African Crustacea. Ann S African Mus. 15:1-55, pls 1-12.

Yaldwyn, J. C. 1960. Crustacea Decapoda Natantia from the Chatham Rise: a deep-water bottom fauna from the New Zealand. Biological Results of the Chatham Islands 1954 Expedition. Part 1. Bull N Z Dept Sci Indust Res. 139:13-56.

Zarenkov NA. 1965. Revision of the genus Crangon Fabricius and Sclerocrangon G. O. Sars (Decapoda Crustacea). Zool Zh. 44:1761-1775. 